\title{
*NC Effects: The case of Lubukusu Phonology
}

\author{
Henry Simiyu Nandelenga, \\ Jaramogi Oginga Odinga University of Science and Technology, Department of Linguistics, Languages and \\ Literature, P. O. Box 210-40601, BONDO - KENYA.
}

\begin{abstract}
NC effects refer to phonological processes that are triggered whenever a nasal sound is prefixed before a consonant in the onset position of the syllable cross-linguistically. Most languages consider a nasalconsonant sequence as a marked onset cluster based on sonority sequencing principles and/or other syllablebased phonotactics. In the traditional rule-based Derivational and Non-Linear Phonology approaches, these processes were explained purely in terms of nasal place assimilation without reference to the syllable structure typology of the specific language. In particular, rule-ordering of the Generative Phonology failed to account for simultaneous processes such as nasal place assimilation alongside post-nasal voicing or hardening. However, in the recent past, Optimality Theory (Prince \& Smolensky 1993/2004) has been able to account for these processes through constraint interaction of markedness and faithfulness. In this paper, it is argued that multiple processes from *NC effects can fruitfully be accounted for through language-particular ranking of universal constraints based on the syllable structure phonotactics. Based on Lubukusu language, it is shown that 'conspiracies' against the ${ }^{*} N C$ onset sequence can be adequately handled through constraint interaction in which high-ranked markedness constraints ensure that marked onset sequences do not emerge. However, the markedness constraints *NC and $* C C$, proposed by Pater $(1996,1999)$ and Archangeli, Moll and Ohno (1998) respectively are not sufficient in accounting for Lubukusu data. An enriched constraint set is proposed to handle the unique typology of Lubukusu *NC effects.
\end{abstract}

Key words: constraints, markedness, faithfulness, harmonic, optimal, ROTB

\section{Introduction}

*NC effect is a phonological phenomenon in which a sequence of a nasal followed by a consonant tends to trigger a number of phonological repair processes to avoid a marked onset cluster. Cross-linguistically, a nasal-consonant onset is considered a marked onset cluster because of some universal and language specific syllable structure phonotactics. In typological studies of *NC effects, (Pater, 1996, 1999 \& 2001), it is reported that languages exploit different repair mechanism to avoid the occurrence of NC onsets in the course of morpheme concatenation and other affixation operations. Consequently, an input consisting of a nasal followed by a voiceless consonant cannot surface optimally but must undergo some repair changes. The output of the sequence is realized differently including the faithful [NT], nasal plus voiced stop [ND], nasalization [NN], denasalization $[\mathrm{TT}]$, nasal deletion $[\mathrm{T}]$ and obstruent deletion $[\mathrm{N}]$. Note: $[\mathrm{T}]$ and $[\mathrm{D}]$ stands for a voiceless and voiced obstruent respectfully, while $[\mathrm{N}]$ represent nasals.

(1) *NC effects (Pater, 1996, 1999, Archangeli et al., 1998)

\begin{tabular}{|l|l|l|l|l|l|l|}
\hline Input form & English & $\begin{array}{l}\text { Puyo Pongo } \\
\text { Quechua }\end{array}$ & Konjo & $\begin{array}{l}\text { Indonesian } \\
\text { Kihehe }\end{array}$ & $\begin{array}{l}\text { Venda } \\
\text { Toba Batak }\end{array}$ & $\begin{array}{l}\text { Kelatan } \\
\text { Malay }\end{array}$ \\
\hline$/ \mathrm{NT} /$ & {$[\mathrm{NT}]$} & {$[\mathrm{ND}]$} & {$[\mathrm{NN}]$} & {$[\mathrm{N}]$} & {$[\mathrm{TT}]$} & {$[\mathrm{T}]$} \\
\hline
\end{tabular}

Kager (1999) provides a similar typology of $* \mathrm{NC}$ effects in which the nasal-voiceless obstruent sequence triggers nasal substitution, nasal deletion, vowel epenthesis, post-nasal voicing and denasalization. He cites languages that utilize deletion as including Kelantan, Venda, Swahili, Maore, English, Greek and Spanish. Other languages that use post-nasal voicing strategy include Japanese, Greek and OshiKwanyama (a western Bantu language). Hayes and Stivers (2000) include languages such as Arusa, Eastern Armenian, and Modern Greek dialects, Waorani, Western Desert Languages and Zoque. Hyman and Ngunga (1997) and Ngunga (2000) report that postnasal voicing is a common phenomenon in Yao, a language spoken across the boundaries of Mozambique, Malawi and Tanzania.

In Yao, postnasal voicing is triggered by a sequence of a Nasal-voiceless consonant, but the nasal deletes if the following consonant is voiced except if it is the alveolar plosive [d]. Hyman (2001) cites Bukusu (Lubukusu), Kinande and Kikuyu (Gikuyu) as having the same postnasal voicing feature. Across languages, post-nasal voicing seems to be prevalent (Maddieson \& Ladefoged, 1993; Pater, 1996, 1999, 2001; Hayes \& Stivers, 1996, 2000, Hyman, 2001) in cases where the following consonant is a voiceless obstruent. However, if 
the following consonant is a voiceless fricative, the preferred process is nasal deletion. Both processes have been explained in terms of phonetics; they have a phonetic basis especially an articulatory explanation.

Conditions when obstruents may be voiced post-nasally have been studied widely (Westbury \& Keating, 1986; Ohala \& Ohala, 1995, among others). It is argued that voicing is realized in speech if the vocal folds are adequately adducted, tensed with enough transglottal airflow. Hayes and Stivers (2000) provide a phonetic account of post-nasal voicing through aerodynamic modeling. According to these authors, rapid buildup of supraglottal air pressure is due to the blockage of airflow in obstruents leading to cessation of transglottal airflow and consequent loss of voicing. Accordingly, voicing may be prolonged if the supraglottal air pressure is avoided or delayed. The authors identify a number of factors that may favour voicing. These factors are pharyngeal expansion, subglottal pressure, vocal fold adjustments, place of articulation and velumrelated factors such as nasal 'leak' and velum rising. Studies of velar movements by Bell-Berti (1993) show substantial co-articulatory effects at the gestural transition between the two segments. It is observed that nasals will tend to engender the voicing of the neighbouring obstruent due to nasal leak. Hayes and Stivers (1996, 2000), show that prenasal voicing is difficult because of the expansion/contraction of the supralaryngeal cavity due to the action of the falling and rising of the velum. Their findings from the vocal tract modeling indicate that compression/rarefaction is crucially responsible for the voicing of obstruents in postnasal position but not in the prenasal position.

Ohala (1995) reports on the cross-linguistic tendency for nasal deletion before voiceless fricatives arguing that it has a phonetic explanation. Through perceptual-based experiments, he observes that the environment of a voiceless fricative after a nasal tends to greatly promote nasal loss and this process is also attested diachronically across languages. Further, it is noted that this phenomenon is responsible for the nasal vowels in French, Hindi and other languages. Voiceless fricatives often promote the nasalization of vowels that precede the nasals that are subsequently lost. In French and Hindi, it is shown that nasals were lost diachronically before a following voiceless fricative and what remains is a nasalized vowel.

(2) Nasal loss in French and Hindi
(i) French
[dã] 'tooth'
(ii) Hindi
[dãt] 'tooth'
Latin
[dens]
Sanskrit [danta]

Historically, according to Ohala, German has preserved most of the nasals unlike its Germanic sister language, English, as shown below in which the lost nasals preceded voiceless fricatives.

(3) Nasal loss in English

$\begin{array}{ll}\text { German } & \text { English } \\ \text { gans } & \text { goose } \\ \text { fünf } & \text { five } \\ \text { unser } & \text { us }\end{array}$

Other cases reported by Ohala (1995) are from Ojibwa, a West African language in which long vowels are nasalized before fricatives. Many dialects of Spanish (Iberian, Chilean) are reported to develop nasal vowels with subsequent loss of the nasals. In Italian, it is prevalent in informal speech as compared to the parent Latin forms. Similar cases are reported from Swahili and Yao, Bantu languages of East Africa. According to Ohala (1995), nasalized vowels are a result of greater than normal glottal opening which spreads to the neighbouring vowels through assimilation. The open glottis has the effects of assumed coupling of the nasal and oral cavity leading to the perception or production of nasal vowels.

However, Hyman (2001) objects to the phonetic grounding of postnasal voicing showing that indeed there are cases in which an input /ND/ is actually realized as [NT], the opposite of what phonetic grounding predicts. Contrary to views expresses by Flemming (1995), Hayes and Stivers $(1995,1996)$ and Pater $(1996$, $1999,2001)$, Hyman shows that the counter example to postnasal voicing $\{/ \mathrm{ND} / \rightarrow[\mathrm{NT}]\}$ is well attested. While there might be principled reasons to incorporate phonetics into phonology, (to argue for postnasal voicing), Hyman (2001:142) argues that there must be limits to 'phonetic determinism'. Although postnasal voicing is prevalent, the author maintains that phonetic determinism is only relevant in diachronic domain. It is argued that languages may favour NT over ND for perceptual reasons. By examining a number of NC processes, it is observed that perception plays a role in motivating postnasal devoicing that may appear a counter-process.

Hyman (2001) reports on four Bantu languages (Tswana, Makua, Punu and Bubi) in which there is postnasal devoicing from the input nasal-voiced obstruent sequence. In Tswana, obstruents devoice after the first person singular object prefix -N, e.g /bóná/ 'see' /N-bóná/ $\rightarrow$ [mpóná] 'see me!'. Based on the Tswana data, Hyman argues that the presence of [b] and [d] but not [mb] and [nd] is because of an active anti-voicing constraint *ND. Consequently, *ND should be conceived as occurring in Tswana and it outranks the *NT 
constraint diachronically based on Proto-Bantu stops and the early Sotho-Tswana forms. The existence of contradictory processes may imply that they are both phonetically driven but by different contradictory demands

This paper, therefore, examines the markedness of a nasal-consonant onset sequence in Lubukusu, a Bantu language spoken in western part of Kenya (Mutonyi, 2000; Nandelenga 2008, 2013). The markedness sets off various repair mechanisms dubbed $* \mathrm{NC}$ effects in the literature. In Optimality Theory (hereafter OT) of Prince and Smolensky (1993/2004) and McCarthy and Prince (1993), these effects are explained in terms of the interaction of markedness and faithfulness constraints. Pater $(1999,2001,2004)$ proposed a markedness constraint *NC to handle nasal-voiceless obstruent sequences while Archangeli et al., (1998) propose a markedness constraint *CC to take care of all cases of a marked nasal-consonant sequence in the onset position that cannot be repaired by the specific *NC constraint of Pater $(1996,1999,2001)$.

In this paper, there are three basic arguments for the *NC effects in Lubukusu. First, it is argued that to fully understand these effects, it is necessary to unravel the syllable structure of the language which constrains the various repair mechanisms. All cases of $* \mathrm{NC}$ onsets that are considered marked are not part of the canonical syllable onset clusters in the language. Secondly, it is argued that Pater's $(1996,1999,2001)$ NC and Archangeli et al.,'s (1998) *CC constraints are both inadequate in handling Lubukusu data without an enriched constraint set. It is shown that $* \mathrm{NC}$ can only handle the nasal plus voiceless obstruent sequence. Similarly, the ${ }^{*} \mathrm{CC}$ constraint does not yield all the attested forms in Lubukusu; it will ban the legitimate NG onset.

In this paper, it is proposed that to fully account for the rich typology of *NC effects in Lubukusu, more constraints must be posited in the language's CON. The third and final argument is that an OT approach is superior in explaining the phonological processes that result from the markedness of NC onsets. In an OT grammar, it is argued that so long as markedness constraints (demanding syllable well-formedness) dominate faithfulness constraints (demanding faithful mapping of the input on to the output), no marked NC onset cluster will emerge. Consequently, simple recourse to constraint interaction of universal constraints, ranked in a language-particular hierarchy, is all that is required to account for the 'homogeneity of target and the heterogeneity of processes' in the words of McCarthy (2002:26).

The study is theoretically anchored in OT, a theory of the grammar of a language whose basic argument is that the grammar of a language is a system of universal constraints. The surface manifestation of the grammar is a result of interaction of markedness and faithfulness constraints that are in conflict which is resolved through constraint ranking. Languages share the same constraints, what differentiates them is the ranking of these universal constraints in a language particular hierarchy, the H. OT assumes a direct mapping between underlying and surface forms. Central in this mapping operation is a set of hierarchically-ranked constraints. Constraints may be sensitive to well-formedness of candidate forms banning marked structures or requiring unmarked forms. Others are sensitive to the correspondence relation between underlying forms and candidate output forms. OT is an output-based theory and thus, an OT grammar's evaluation is surface-based (McCarthy, 2002). The relation between the input and the output is mediated by two formal mechanisms, GEN and EVAL. GEN (Generator) creates the linguistic objects and notes their faithfulness relation to the input under consideration. EVAL (Evaluator) uses the language's hierarchy to select the best candidate(s) for a given input from among the candidates produced by GEN. The constraint hierarchy of a language is its particular ranking of CON, the universal set of constraints. These are the core universal elements of an OT grammar.

Figure 1: Basic OT Architecture (after McCarthy, 2002:10).

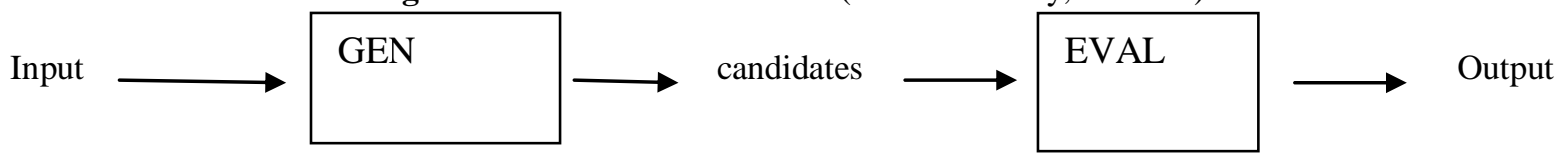

Formalized model of OT (after Archangeli \& Langendoen, 1996)

1. GEN for a given input, the Generator creates a candidate set of potential outputs

2. EVAL from the candidate set, the Evaluator selects the best (optimal) output for that input.

3. CON EVAL uses the language particular ranking of constraints from the universal set of Constraints.

The output form is optimal if it incurs the least serious violations of a set of conflicting constraints. That is, for a given input, the grammar selects the optimal candidate which is the actual output and evaluations

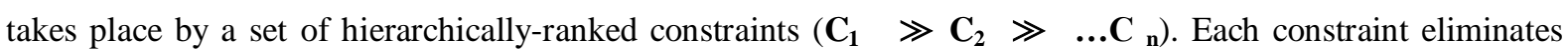


some output until only one candidate survives as optimal. The optimal output candidate is the 'most harmonic' candidate (d) below based on the ranking $\mathrm{C}_{1} \gg \mathrm{C}_{2} \gg \mathrm{C}_{n}$

Figure 2: Input-Output Mapping in an OT Grammar (Kager, 1999:8).

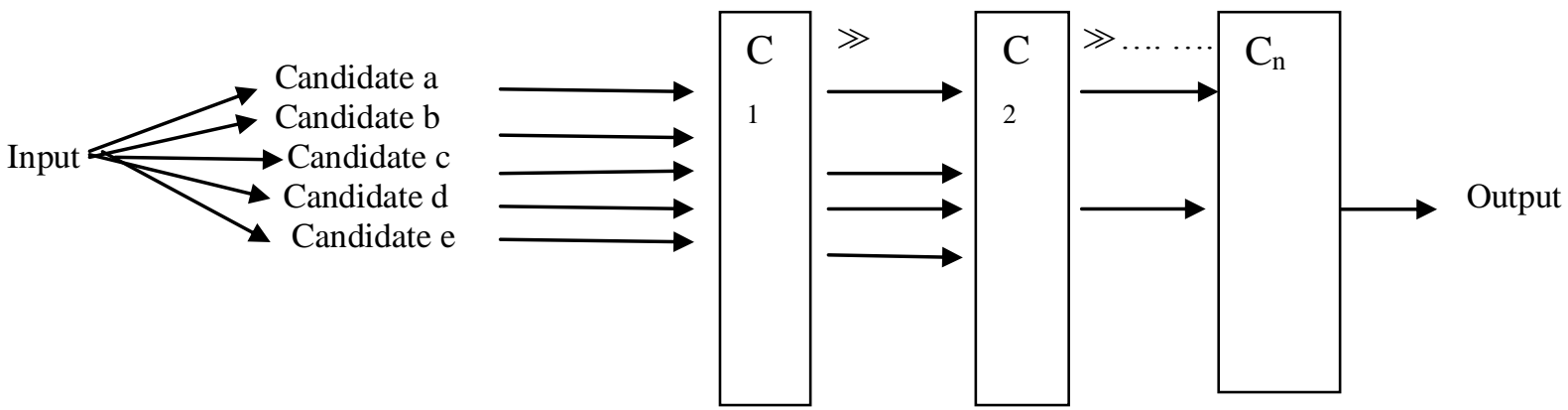

This paper is organized as follows. Section 2 provides the syllable structure of Lubukusu and how it constrains the attested *NC effects in the language, in particular, the preference for CG onset. In section 3, I provide data in Lubukusu exhibiting a typology of *NC effects and show how Pater (1996, 1999) and Archangeli et al., (1998) proposed markedness constraints can only partially explain the attested repair strategies of the language. I also offer an alternative and enriched constraint set to handle all cases of NC effects in the language. Section 4 gives a summary of how constraint-based analysis is preferable to the rule-based derivational approach.

\section{The Syllable Structure Of Lubukusu}

Studies on the Lubukusu phonology (1974; Mutonyi, 2000; Nandelenga, 2008, 2013; Nganga, 2008; Wasike, 2004) indicate that the Lubukusu syllable can be divided into four syllable structure types. These four types are as follows; the CV (Consonant Vowel) type, the CCV (Consonant Consonant Vowel) type, the V (Vowel only) type and the N (syllabic nasal) type. The language also has long vowels which are the contrastive (distinctive) counterparts of the above short monophthongs. The syllable structure is summarized in (3).

(3) The syllable structure typology of Lubukusu.

(a) CV (V);

(b) $\mathrm{CCV}$ (V);

(c) $\mathrm{V}(\mathrm{V})$;

The Consonant + Vowel type (the canonical and unmarked type)

(d) $\mathrm{N}$;

The Consonant + Glide + Vowel type (the only cluster allowed)

The Onsetless syllable type (headed by short or long vowel)

Syllabic nasal type (the only syllabic consonant allowed).

The CV syllable type is the most common in Lubukusu language as is the case across many languages and considered the most unmarked of all syllable types (Blevins, 1995; de Lacy, 2004; Cairns \& Reimy, 2011; Goldsmith, 2011). In Lubukusu, all consonants can occupy the onset position in the CV structure. The consonant phonemic inventory is as shown in (4).

(4) The Lubukusu consonant inventory (Mutonyi, 2000; Nandelenga, 2008, 2013)

\begin{tabular}{|c|c|c|c|c|c|}
\hline & Bilabial & Labial-dental & Alveolar & Palatal & Velar \\
\hline Plosives & $\overline{p p}$ & & $\overline{\mathrm{t}}$ & $\overline{c c}$ & $\overline{\mathrm{k}}$ \\
\hline Fricatives & $\beta$ & $\mathrm{f}$ & $\mathrm{s}$ & & $\mathrm{x}$ \\
\hline Nasals & $\mathrm{m}$ & & $\mathrm{n}$ & $\mathrm{n}$ & $\mathrm{g}$ \\
\hline Liquids & & & $1, \mathrm{r}$ & & \\
\hline Glides & & & & j & $\mathrm{w}$ \\
\hline Pre-nasal stops & ${ }^{\mathrm{m}} \mathrm{b}$ & & ${ }^{\mathrm{n}} \mathrm{d}$ & ${ }^{\mathrm{n}}$ & $\mathrm{g}$ \\
\hline
\end{tabular}

The data that follow, based on consonants from all the manner of articulation types, show the CV structure type in Lubukusu. The relevant CV syllable is word initial in the data.

(5) CV syllable structure

\begin{tabular}{|c|c|c|c|}
\hline Manner type & Input & Output & Gloss \\
\hline (a) Plosive; & /kana/ & [ka.na] & 'desire(V)' \\
\hline (b) Fricative & /soka/ & [so.ka] & 'swim' \\
\hline (c) Nasal & /nula/ & [nu.la] & 'be sweet' \\
\hline (d) Prenasal & $/ \mathrm{mbea} /$ & {$\left[{ }^{\mathrm{m}}\right.$ be.a] } & 'I lie' \\
\hline
\end{tabular}



(e) Liquid
/lila/
[li.la]
'cry'
(f) Glide
/juja/
[ju.ja]
'hurry up'

Lubukusu has a CCV syllable structure that is restricted to the CGV (Consonant, Glide, Vowel). Lubukusu prohibits consonant clusters of any other kind in the onset (Mutonyi, 2000; Wasike, 2004; Nandelenga, 2013) except the CG type. The preference (unmarked state) of the CV type and the avoidance (markedness) of the CCV clusters is often explained in terms of ease of articulation and perceptual distinctiveness between the segments making up the cluster (Chotoran et al., 2002; Johnson, 2003; Flemming, 2004; Raphael et al., 2007).

Both articulatory and perceptual studies show that it is easier to produce and perceive a CV syllable than a CCV or any other cluster. This explains why in languages in which consonant clusters are allowed, there are clear restrictions on the segment type and the sequencing that may be permissible (Blevins, 1995; Morelli, 2003; Smith, 2003). Indeed, a number of languages simplify onset clusters to the simple CV through vowel epenthesis and consonantal deletion. In Lubukusu, there are two glides; the voiced palatal glide [j] and the voiced labio-velar glide [w]. These glides can follow any consonant in the onset position to form a cluster except another glide (there is no sequence of GGV) due to the active OCP (Obligatory Contour Principle) effects which in OT, is formulated as a markedness constraint (Myers, 1997). In addition, the language has no geminates. There are a number of phonetically based explanations as to why glides are preferred in pre-nuclear position based on articulatory, acoustic and perceptual studies.

First, glides have vowel like characteristics due to the open stricture, they can follow any consonant without obscuring its perception. This is true especially for the stops whose perception depends on the release burst (Chotoran et al., 2002). Gestural overlap in the stop release phase may preclude this audible burst (Browman \& Goldstein, 1990; Byrd, 1992; Byrd \& Choi, 2009). Second, a glide has a high sonority index than other consonant in the sonority hierarchy ensuring that the resultant onset cluster respects the Sonority Sequencing Principle (SSP) constraint (Morelli, 2003) of the language. The pre-onset consonant would be of low sonority ensuring a rising sonority to the syllable peak. The CGV data is as shown in (6).

(6) The CGV syllable type in Lubukusu monosyllabic words.

\section{(A) $\mathrm{CjV}$ type}
(a) Plosives:
(i) $/ \mathrm{pje} /$
(b) Fricatives:
(i) $/ \mathrm{sja} /$
(i) $/ \mathrm{nja} /$
(d) Prenasals:
(i) $/ \mathrm{N}-1 \mathrm{ja} /$
(e) Liquids:
(i) /rja/

(B) $\mathrm{CwV}$ type

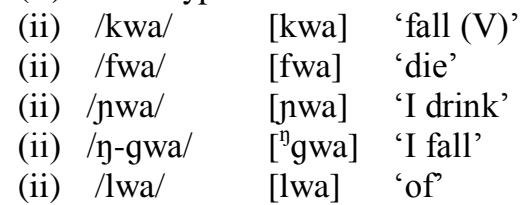

In principle, Lubukusu has syllables with onsets but it also has onsetless syllables. There are syllables headed by vowels only at word initial, medial and final positions and this includes monosyllables, disyllables and polysyllabic words either with short or long vowels as in (7).

(7) The V syllable structure type

\begin{tabular}{|c|c|c|c|c|}
\hline $\begin{array}{l}\text { (i) Input Output } \\
\text { (a) } / \mathrm{ao} /[\mathrm{a} . \mathrm{o}]\end{array}$ & $\begin{array}{l}\text { Gloss (ii) } \\
\text { 'there }\end{array}$ & $\begin{array}{l}\text { Input } \\
\text { /ano/ }\end{array}$ & $\begin{array}{l}\text { Output } \\
\text { [a.nol }\end{array}$ & $\begin{array}{l}\text { Gloss } \\
\text { 'here' }\end{array}$ \\
\hline eno/ [e.no] & 'this side' & lea/ & {$[\mathrm{e} . \mathrm{i}]$} & 'this one' \\
\hline / [i.xa] & 'descend' & /ima/ & [i.la] & 'take to' \\
\hline ona/ [o.na] & 'heal' & /oja/ & [o.ja] & 'you burn' \\
\hline
\end{tabular}

The final syllable type is that of a syllabic nasal. Lubukusu allows nasals to function as syllabic consonants; $[\mathrm{N}]$. The syllabic consonants are often used to break unacceptable onset clusters. Lubukusu nasals are the only consonants that are known to be moraic (Mutonyi, 2000; Nandelenga, 2008, 2013), besides being sonorants, hence can be syllabic. Only one environment engenders this type of syllabification: when two nasals follow each other.

In Lubukusu, there is an archiphoneme /N/ sound that also, morphologically, stands for first person singular morpheme prefix (the $1^{\text {st }}$ person singular ' $\mathrm{I}$ ' in English). It is realized differently on the surface depending on the following consonant's place of articulation. This is because it has long been argued that nasals are underlyingly unspecified for the place feature [place] (Durand, 1994). Consequently, in assimilation processes, the prefix nasal acquires the place of articulation of the following consonant sound. Whenever the /N/ archiphoneme is prefixed to a stem/root beginning with a nasal, it is transformed into a syllabic nasal in Lubukusu and shares its [place] feature. This is evident in the following data having the four Lubukusu nasals. 
(8) Syllabic Nasals in Lubukusu.

\begin{tabular}{|c|c|c|c|}
\hline Prefix 'I'+ stem & Surface form & English gloss & \\
\hline (a) Alveolar nasal & & [n.na. $\beta a]$ & 'I weave' \\
\hline (b) Bilabial nasal & /N-mala/ & [m.ma.la] & 'I complete' \\
\hline (c) Palatal nasal & /N-nala/ & [n.na.la] & 'I can/ am able' \\
\hline (d) Velar nasal & /N-yona/ & [y.yo.na] & 'I make' \\
\hline
\end{tabular}

From the above syllable structure of Lubukusu, it is possible to show how it constrains the NC effects and the unmarked status of the CGV syllable type. In OT, it is assumed that markedness constraints evaluate $\mathrm{CGV}$ as the most harmonic cluster. To determine the restriction placed on other onset clusters, it is necessary to construct a harmonic scale of the possible Lubukusu onset clusters. In the scale, the specification is thus; the initial $\mathrm{C}$ stands for the pre-onset consonant, the following $\mathrm{O}=$ Obstruent, $\mathrm{F}=$ Fricative, $\mathrm{N}=$ Nasal, $\mathrm{L}=$ Liquid and finally, $\mathrm{G}=$ Glide.

(9) Harmonic/markedness scale of Lubukusu onset clusters (Nandelenga, 2013)

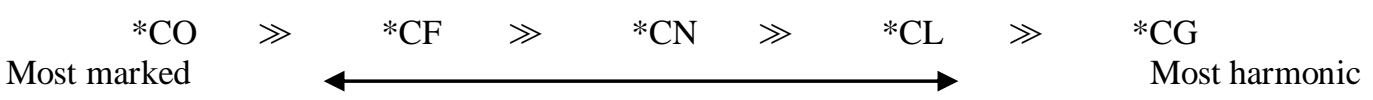

The far left of the markedness scale indicates the cluster that is the most marked in having either a sonority plateau (e.g. [*pk], [*nn], [*sg], onsets) or sonority reversal (e.g. [*ns], [*lp], [*wk], onsets). The far right represents the most harmonic cluster. The above scale can be converted into markedness constraints in which the non-occurring clusters are assumed to be undominated constraints. This gives a markedness ranking as follows; *CO, *CF, *CN, *CL, $*^{*} \mathrm{CG}$. Such constraints are part of a family of constraints subsumed under the general anti-cluster constraint; *COMPLEX ${ }_{\text {ONSET }}$. The *CG constraint may be defined as follows; 'a cluster of the form 'Consonant-Glide' sequence is not allowed in the onset'. Such a constraint is considered a prohibiting markedness constraint and is conventionally preceded by the asterisk $(*)$.

In determining the unmarked status of CG onset cluster, the undominated markedness constraints will be *CO and *CF while the *CG is low-ranked in the analysis of the Lubukusu inputs having a CG onset; /fwa/ 'die' and /twa/ 'nothing'. Faithfulness constraints ensure that input segments are not deleted to avoid the marked clusters or epenthetic segments used to break up the clusters. Faithfulness constraints MAX-IO, which prohibits deletion and DEP-IO, which prohibits epenthesis of segments in the output, are included. These two constraints are ranked above the ${ }^{*} \mathrm{CG}_{\text {ONSET }}$ markedness constraints to allow for faithful parsing of CG clusters of the language.

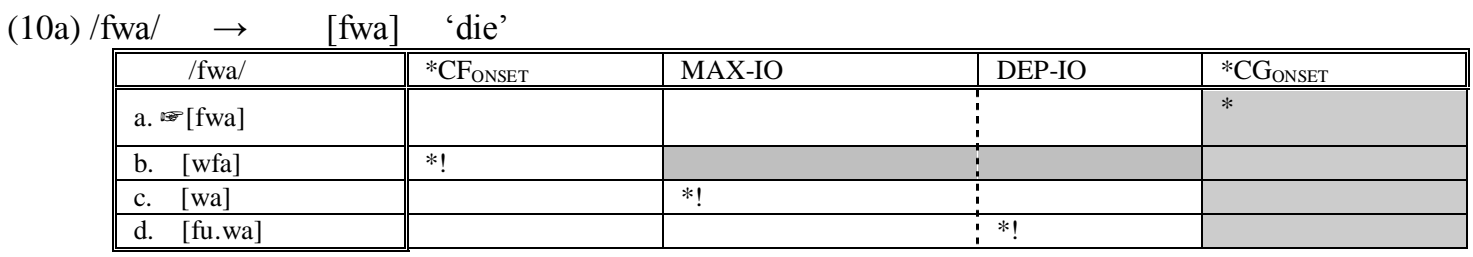

The optimal candidate violates the low ranking constraint but satisfies the undominated markedness constraint; ${ }^{*} \mathrm{CF}_{\text {ONSET }}$. Candidate (b) exhibits a sonority reversal. The two other candidates violate the faithfulness constraints that demand input-output correspondence through deletion in candidate (c) and epenthesis in (d). Candidate (b) also violates the undominated SSP constraint (Kager, 1999; 2004; Morelli, 2003; Yu Cho \& King, 2003) of the language. Consequently, it is possible to recast the above tableau by replacing the ${ }^{*} \mathrm{CF}_{\mathrm{ONSET}}$ constraint with the SSP because the violation incurred by candidate (b) is that of sonority reversal

$(10 \mathrm{~b}) / \mathrm{fwa} / \mathrm{f} / \mathrm{fwa}]$ 'die'
\begin{tabular}{|l||l|l|l|l|}
\hline \multicolumn{1}{|c|}{$/ \mathrm{fwa} /$} & SSP & MAX-IO & DEP-IO & ${ }^{*}$ CG \\
\hline \hline a. $[\mathrm{fwa}]$ & & & & $*$ \\
\hline b. $[\mathrm{wfa}]$ & $* !$ & & & \\
\hline c. $[$ wa] & & $* !$ & $* !$ & \\
\hline d. $[$ fu.wa] & & & & \\
\hline
\end{tabular}


The optimal candidate is the same as in the preceding tableau. However, the rationale for introducing SSP instead of $* \mathrm{CF}_{\mathrm{ONSET}}$ is based on the realization that it is possible to violate the $* \mathrm{CF}_{\mathrm{ONSET}}$ without incurring violation marks for SSP. For example, having a voiceless plosive plus a voiceless fricative [*ts, *pf] does not

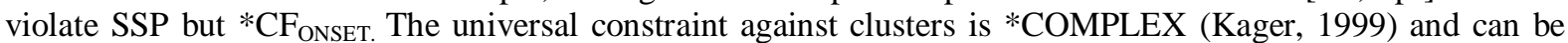
relativized to specific positions in the syllable; *COMPLEX ${ }_{\text {ONSET }}$ (Kager, 1999; McCarthy, 2004) because this is the only position with a cluster (the language has no coda consonants). This constraint states that no more than one consonant may be associated with the onset position of the syllable, (onsets are simple). In Lubukusu, the ranking of ${ }^{*}$ COMPLEX ${ }_{\text {ONSET }}$ must allow for the faithful parsing of the CG cluster, therefore, this constraint should be dominated by some faithfulness constraints that require underlying input segments [i.e. CG] to be parsed. The ranking should be as follows: SSP, $* \mathrm{CO} \gg \mathrm{MAX}-\mathrm{IO}, \mathrm{DEP}-\mathrm{IO} \gg * \mathrm{CG}, \mathrm{COMPLEX} \mathrm{ONSET}_{\mathrm{O}}$.

$(11) /$ twa $\rightarrow$ [twa $\rightarrow$ 'nothing'

\begin{tabular}{||l||l|l|l|l|l|l||}
\hline \multicolumn{1}{|c|}{$/$ twa/ } & SSP & $*$ CO & MAX-IO & DEP-IO & $*$ CG & $*$ COMP \\
\hline \hline a. $[\mathrm{twa}]$ & & & & $*$ & $*$ \\
\hline b. $[\mathrm{wta}]$ & $* !$ & $*$ & & & & $*$ \\
\hline c. $[\mathrm{wa}]$ & & $* !$ & & & $\vdots$ \\
\hline d. $[\mathrm{ti} . \mathrm{wa}]$ & & & & $* !$ & & \\
\hline
\end{tabular}

In the tableau, it is apparent that the violation of the low-ranked constraint against the complex onset is of no consequence because the optimal candidate violates the constraint but with little effect on its harmony visa-vis other competitors. Interaction of markedness constraints; ${ }^{*} \mathrm{CO},{ }^{*} \mathrm{CF}, \mathrm{SSP},{ }^{*} \mathrm{CG}$ and COMPLEX $\mathrm{ONSET}$ on one hand, and the faithfulness constraints; MAX-IO and DEP-IO on the other hand, enable us to determine the optimal cluster of the Lubukusu syllable structure. The constraint hierarchy of Lubukusu optimal onset cluster

$[\mathrm{CG}]$ is as follows; *CO, CF, CN, CL, NN, SSP $\gg$ MAX-IO, DEP-IO $\gg * C G, *$ COMPLEX ${ }_{\text {ONSET. }}$

\section{III. *NC Effects In Lubukusu Phonology}

In this section, I provide a typology of NC effects showing the markedness of a nasal-consonant sequence and how this markedness is determined by the syllable structure of Lubukusu. In the data, it is shown that $* \mathrm{NC}$ effects are not limited to nasal-voiceless obstruent sequence but, it targets other NC sequences some of which have voiced post-nasal consonants, hence the inadequacy of the *NC constraint. The *NC typology has the following onset sequences; a nasal-voiceless plosive (repaired through post-nasal voicing), a nasal-voiceless fricative (repaired through nasal deletion), a nasal-voiced fricative (repaired via post-nasal hardening) a nasalliquid (repaired via post-nasal hardening) and the nasal-nasal sequence which is also marked (repaired through formation of syllabic nasal).

This typology follows from the fact that all the *NC onset clusters violate the canonical consonant cluster that is permissible in Lubukusu; the CG cluster. Based on the syllabic phonotactics of the language, no onset cluster can be optimal except a nasal-glide sequence as constrained by the syllable structure types discussed above. In the following examples, the Lubukusu archiphoneme [N] (also the first person morpheme prefix, the $1^{\text {st }}$ person singular ' $I$ ' in English) is normally prefixed to various roots beginning with any of the consonants of Lubukusu and they result in a verb that states 'I do something' as indicated below.

(12) Lubukusu typology of *NC effects Input Output Gloss

(a) $/ N-$ texa/ [ de:xa] 'I boil'

(b) $/ \mathrm{N}-$ fuka/ [fuka] 'I cook'

(c) $/ \mathrm{N}-\beta$ ala/ [ ba.la $] \quad$ 'I count'

(d) $/ \mathrm{N}$-lima/ [ ${ }^{\mathrm{n}}$ di.ma $] \quad$ 'I cultivate'

(e) $/ \mathrm{N}-$ nala/ [n.na.la] 'I get used'

\section{Repair mechanism}

Place assimilation and post-nasal voicing. Nasal deletion.

Place assimilation and post-nasal hardening.

Place assimilation and post-nasal hardening.

Formation of syllabic nasals.

It can be inferred from the data that the presence of a nasal followed by a consonant of any kind, except the canonical glide, will induce some repair mechanism including nasal place assimilation, post-nasal voicing hardening (formation of prenasalized stops) and the formation of syllabic nasals. The type of repair adopted varies and is dependent on the phoneme type that follows the nasal. An examination of each *NC effect and an OT account determining the output repairs and the constraints ranking is given in the following analysis. 


\subsection{No Nasal + Voiceless Plosive Onset}

Lubukusu has four voiceless plosives spread across four places of articulation as follows; the labial [p], alveolar [t], the palatal [c] and the velar [k]. The data below show that whenever a nasal sound is followed by any of the four voiceless plosives, the cluster is repaired through nasal place assimilation and postnasal voicing of the voiceless plosive resulting in prenasalized stops at the four places of articulation.

(13) Nasal-voiceless stop onset cluster

\begin{tabular}{|c|c|c|c|}
\hline Input & Output & Gloss & Repair mechanism \\
\hline ara/ & [ ba.ra] & 'I think' & \\
\hline exa/ & $\begin{array}{l}{[\mathrm{de} \cdot \mathrm{xa}]} \\
{\left[{ }^{\mathrm{n}} \mathrm{fu} \cdot \mathrm{ma}\right]}\end{array}$ & $\begin{array}{l}\text { 'I boil' } \\
\text { 'I work' }\end{array}$ & $\begin{array}{l}\text { Nasal place assimilation and post-nasal } \\
\text { voicing. }\end{array}$ \\
\hline & [ gu.la] & 'I buy' & \\
\hline
\end{tabular}

In the data (13), the archiphoneme prefix nasal /N/ that is unspecified for place feature assimilates to the place of articulation of the following voiceless verb root consonant. For example, the underlying nasal acquires the labial feature [+labial] from $/ \mathrm{p} /$ and is realized on the surface as $/ \mathrm{m} /$. Assimilation of place takes place simultaneously with that of voice so that the voiceless plosive acquires the [+voice] specification of the inherently voiced nasal stop. The output is the voiced bilabial prenasalized stop; the [ $\left.{ }^{\mathrm{m}} \mathrm{b}\right]$ in $(13 \mathrm{i})$, at the alveolar place, the result is the voiced alveolar prenasalized stop $\left[{ }^{n} \mathrm{~d}\right]$, at the palatal place, the voiced palatal prenasalized stop $\left[{ }^{\mathrm{n}} \mathrm{f}\right]$ and finally, at the velar place, the result is the voiced velar prenasalized stop, the $\left[{ }^{\mathrm{n}} \mathrm{g}\right]$.

What is clear from these examples is that no nasal can be followed by a voiceless plosive in the surface output. This can be explained from the syllable structure typology discussed in $\S 2$. There is no onset cluster of the type CO (nasal-voiceless plosive); a marked onset prohibited by the grammar of Lubukusu. Pater (1996, 1999 , 2001) propose that a universal constraint; *NÇ, is responsible for the markedness of this cluster in the phonology of many languages and it is undominated in the constraint hierarchy thus banning NÇonsets clusters.

In an OT account, when the voiceless plosive acquire the [+voice] feature of the nasal, there is a violation of the voicing correspondence between the input and the output shown by co-indexing notation. This violates IDENT-IO (voice). In addition, by acquiring the nasal feature, the oral voiceless stop also violates the faithfulness constraint IDENT-IO (nasal). The two faithfulness constraints interact with the markedness constraint $* \mathrm{NC}$ to determine the optimal repair of the onset cluster. The $* \mathrm{NC}$ is an undominated in the constraint hierarchy of Lubukusu; it induces the violation of the two faithfulness constraints ranked below it as in (14).

\begin{tabular}{|c|c|c|c|}
\hline (14). $/ \mathrm{N}_{1}-\mathrm{t}_{2} \mathrm{exa} /$ & {$\left[\mathrm{d}_{12}\right.$ e.xa] } & & \\
\hline$=/ \mathrm{N}_{1}-\mathrm{t}_{2} \mathrm{exa} /$ & *NCC & "IDENT-IO(voi) & "IDENT-IO(nas) \\
\hline $\mathrm{a}_{\text {. }}{ }_{\mathrm{d}}^{\mathrm{n}} \mathrm{d}_{12}$ e.xa] & & 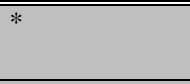 & "* \\
\hline b. $\mathrm{n}_{1} \mathrm{t}$ e.xa & $* !$ & & \\
\hline
\end{tabular}

The optimal candidate is the one in which the nasal has undergone assimilation to the following obstruent causing the plosive to acquire its nasal and voice features. The voiceless plosive [t] becomes a voiced pre-nasalized stop [ $\left.{ }^{\mathrm{n}} \mathrm{d}\right]$. Although candidate (a) has more violations than the competitor, due to strict domination, the violation of low-ranked constraints is tolerated unlike the high-ranked constraints. The losing candidate violates the undominated markedness constraints (*NC). However, it is possible for the input $/ \mathrm{N}_{1}-\mathrm{t}_{2} \mathrm{exa} /$ to be realized in more than one form in the output e.g. $\left[\mathrm{n}_{1} . \mathrm{t}_{2}\right.$ e.xa], based on the 'Richness of the Base (ROTB) principle (Smolensky, 1996) which states that there is no limit to the number of candidate outputs that GEN can emit for evaluation. $\left[\mathrm{n}_{1} . \mathrm{t}_{2}\right.$ e.xa], candidate would emerge optimal based on the three constraints proposed above because it does not violate the *NC but another constraint; the *CODA, assuming that the nasal forms the coda of a preceding syllable. We need the constraint *CODA, to rule out this candidate as optimal. It should be noted that in Bantu languages in which syllables are invariably open, the *CODA constraint is not violated and so in Lubukusu.

Finally, within the OT account of Correspondence Theory (McCarthy \& Prince, 1995), assimilation also violates the correspondence relation between the input and output, a form of coalescence in which two input segments $/ \mathrm{N}+\mathrm{t} /$ are fused and realized in the output as one segment, the prenasalized [ $\left.{ }^{\mathrm{n}} \mathrm{d}\right]$. In this study, we adopt the view that a pre-nasal stop is one segment and not a sequence of consonants (Mutonyi, 2000; Nandelenga, 2008). In this context two segments in the input are mapped on to one in the output, a violation of a faithfulness /correspondence constraint; UNIFORMITY-IO. It is violated by the optimal candidate, hence it 
must be ranked below *NC.. UNIFORMITY-IO (McCarthy, 2002, 2004) requires that no element of the output has multiple correspondents in the input.

\begin{tabular}{|c|c|c|c|c|c|}
\hline \multicolumn{2}{|c|}{ (15) $/ \mathrm{N}_{1}-\mathrm{t}_{2} \mathrm{exa} / \rightarrow\left[\mathrm{d}_{1,2}\right.$ e.xa $]$} & & & & \\
\hline$/ \mathrm{N}_{1}-\mathrm{t}_{2} \mathrm{exa} /$ & *NÇ & *CODA & IDENT-IO ${ }_{\text {vol }}$ & IDENT-IO ${ }_{\text {NAS }}$ & UNIFORM-IO \\
\hline 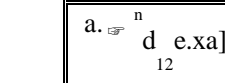 & & & * & ** & "* \\
\hline b. $\mathrm{n}_{1} \cdot \mathrm{t}$ e.xa & & $* !$ & & & \\
\hline c. $\mathrm{n}_{1} \mathrm{t}$ e.xa & $* !$ & & & & \\
\hline
\end{tabular}

The optimal candidate (a) violates the newly introduced UNIFORMITY-IO constraint, but this constraint is low-ranked and, therefore, the violation is not fatal. However, candidate (b) violates the undominated constraint; ${ }^{*} \mathrm{CODA}$, incurring a fatal violation mark as a result.

Two other candidates are possible from the given input; one that deletes the initial nasal resulting in [ $\left.\mathrm{t}_{2} \mathrm{e} . \mathrm{xa}\right]$, and another that inserts a vowel between the initial nasal and the following alveolar plosive $\left[\mathrm{n}_{1}\right.$ i.t. $\left.\mathrm{t}_{2} \mathrm{e} . \mathrm{xa}\right]$. These two candidates violate two faithfulness constraints; the anti-deletion, MAX-IO and the anti-epenthesis, DEP-IO. In Lubukusu syllabification, the IDENT-IO family of constraints is consistently violated to satisfy high-ranked constraints (Nandelenga, 2013). This implies that MAX-IO and DEP-IO are ranked above the IDENT-IO constraints in the tableau.

\begin{tabular}{|c|c|c|c|c|c|c|c|}
\hline 16). $/ \mathrm{N}_{1}-\mathrm{t}_{2} \mathrm{exa} /$ & $\rightarrow$ & {$\left[\mathrm{d}_{1,2}\right.$ e.xa] } & 'I bo & & & & \\
\hline$/ \mathrm{N}_{1}-\mathrm{t}_{2} \mathrm{exa} /$ & *NÇ & *CODA & MAX-IO & " DEP-IO & $\begin{array}{l}\text { IDENT } \\
\text { (nas, voi) }\end{array}$ & $\begin{array}{l}\text { IDENT } \\
\text { (voi, nas) }\end{array}$ & $\begin{array}{l}\text { UNIFORM- } \\
\text { IO }\end{array}$ \\
\hline a. ${ }_{\mathrm{d}}^{\mathrm{n}}$ e.xa & & & & & $\overline{* *}$ & " & $\overline{* *}$ \\
\hline b. $\mathrm{n}_{1} \cdot \mathrm{t}_{2} \mathrm{e} \cdot \mathrm{xa}$ & & $* !$ & & & & & \\
\hline c. $n_{1} t_{2}$ e.xa & $* !$ & & & & & & \\
\hline d. $t_{2}$ e.xa & & & $* !$ & & & & \\
\hline e. $n_{1}$ i. $t_{2}$ e.xa & & & & $* !$ & & & \\
\hline
\end{tabular}

It can be concluded that the markedness constraint $* \mathrm{NC}$ interacting with other constraints yield the correct output from $/ \mathrm{N}+\mathrm{t} /$ input. However, an examination of another form of *NC 0 onset type (nasal + voiceless fricative) should shed more light on the proposed constraints and ranking.

\subsection{No Nasal + Voiceless Fricative Onset}

Another type of the *NC effects in Lubukusu phonology is triggered by the sequence of a nasal and a voiceless fricatives. Generally, this sequence is a marked onset cluster as shown in the syllable structure typology in $\S 2$. The phonological process in Lubukusu that prevents the occurrence of this sequence is nasal deletion before the two voiceless fricatives of the language.

(17) Nasal-voiceless fricative onset cluster

$\left.\begin{array}{lll}\text { Input } & \text { Output } & \text { Gloss } \\ / \mathrm{N}-f u k a / & \text { [fuka] } & \text { 'I cook' } \\ / \mathrm{N}-\mathrm{fwara} / & \text { [fwara] } & \text { 'I dress' } \\ / \mathrm{N}-\mathrm{sixa} / & \text { [sixa] } & \text { 'I burry' } \\ / \mathrm{N}-\mathrm{sa} \beta \mathrm{a} / & \text { [saßa] } & \text { 'I beg' }\end{array}\right\} \begin{aligned} & \text { Repair mechanism } \\ & \text { Deletion of the prefix nasal }\end{aligned}$

The data reveal that nasals will delete when prefixed before a voiceless fricative. What is interesting though is that it is the prefix nasal that deletes rather than the root consonant. From experimental phonetics, it has been observed that this is a cross-linguistic tendency (Ohala, 1995; Padgett, 1995; Ohala \& Ohala 1993; Ohala \& Kawasaki 1997; Hayes \& Stivers 1996, 2000). For the air entrance to the nasal chamber, the velopharyngeal port must be closed during nasal production but open for the fricatives. Fricative production requires a lot of air to go through the oral cavity to provide sufficient pressure through the narrowed passage to 
cause frication (turbulence). As a result, the nasal production is terminated because most of the air is channeled through the oral cavity rather than the nasal cavity. Note that nasal resonance is mandatory for nasals which require velum lowering (Johnson, 2003; Raphael et al., 2007; Demolin, 2007). Nasals are also weak based on the strength/fortition-lenition scale as compared to the fricatives that follow them in articulation. In addition, the elongation of the vocal tract from the opening of the velopharyngeal port is also responsible for the weak intensity of nasal sounds. Weak sounds are prone to deletion, Lass (1984) notes that lenition (weakening) leads to sound loss (deletion). The sonority scale may be the inverse of a strength scale as follows;

(18) Strength scale

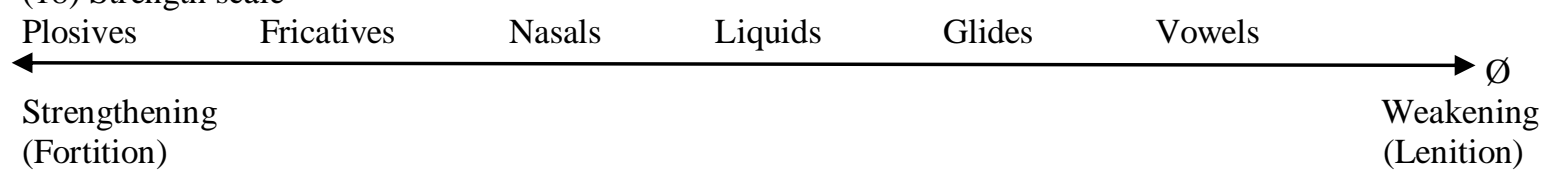

From this scale, it is clear that the end point of any weakening processes in phonology is sound loss. In Lubukusu, there are cases of strengthening (hardening) in which liquids and voiced fricatives harden to prenasalized stops. The above scale makes it clear that any movement from a liquid or fricative to a plosive involves strengthening. Ohala (1997) indicate that it is almost impossible to have nasalized fricatives because the geometry of the vocal tract and aerodynamic constraints make their existence problematic. From perceptual and aerodynamic reasons, it is difficult for fricatives to combine with nasals hence lack of prenasalized fricatives unlike the stops. More oral flow would extinguish voicing in nasals and this is responsible for the rare occurrence of voiceless nasals. Finally, more nasalization would extinguish frication hence lack/rare occurrence of nasal-fricative cluster and prenasalized fricatives in world languages.

OT's constraints are phonetically grounded; their interaction is responsible for the preservation of the initial root consonant due to root faithfulness (Downing, 2006;) or positional faithfulness (Beckman, 1999; Lombardi, 1999; Steriade, 1999). According to the root faithfulness view, if root faithfulness constraints are ranked above the anti-deletion constraints, the root consonant will be preserved and so are positional faithfulness constraints that protect initial syllables against deletion. If *NÇ outranks MAX-IO, it drives the deletion of the initial nasal.

$(19) / \mathrm{N}_{1}-\mathrm{f}_{2} \mathrm{uka} / \rightarrow\left[\mathrm{f}_{2} \mathrm{uka}\right]$ 'I cook'

\begin{tabular}{|l||l|l|}
\hline$/ \mathrm{N}_{1}-\mathrm{f}_{2} \mathrm{uka} /$ & $* \mathrm{NC}$ & MAX-IO \\
\hline a. $\left[\mathrm{f}_{2} \mathrm{uka}\right]$ & & $*$ \\
\hline b. $\left[\mathrm{n}_{1} \mathrm{f}_{2} \mathrm{u} . \mathrm{ka}\right]_{0}$ & $* !$ & \\
\hline
\end{tabular}

Candidate (a), satisfies the undominated markedness constraint prohibiting the nasal-fricative onset sequence. In avoiding the marked cluster, syllabifying the nasal as the coda of the preceding syllable is not an option because *CODA is undominated in the language's hierarchy. In addition, the root consonant is not

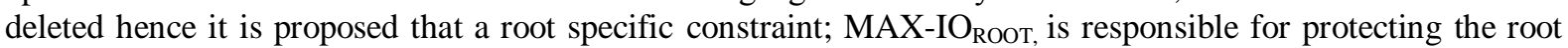
initial consonants from deletion and it must dominate the general MAX-IO constraint as shown in the tableau that follows.

\begin{tabular}{|c|c|c|c|c|}
\hline (20) $/ \mathrm{N}_{1}-\mathrm{f}_{2} \mathrm{uka} /$ & [f $\left.\mathrm{f}_{2} \mathrm{u} . \mathrm{ka}\right]$ & & & \\
\hline$/ \mathrm{N}_{1}-\mathrm{f}_{2}$ u.ka/ & ${ }^{*} \mathrm{NC}$ & ${ }^{*} \mathrm{CODA}$ & MAX-IO & MAX-IO \\
\hline a. $\left[f_{2}\right.$ u.ka] & & & & $*$ \\
\hline b. $\left[\mathrm{n}_{1} \mathrm{f}_{2} \mathrm{u} . \mathrm{ka}\right]$ & $* !$ & & & \\
\hline c. $\left[\mathrm{n}_{1}, \mathrm{f}_{2} \mathrm{u} . \mathrm{ka}\right]$ & & $* !$ & & \\
\hline d. [n $\mathrm{n}_{1}$ u.ka] & & & $* !$ & \\
\hline
\end{tabular}

The information in the tableau shows that the optimal candidate (a) violates the general MAX-IO

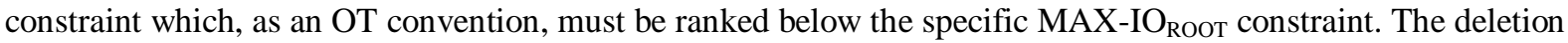
of the nasal consonant involves a loss of correspondence between the input and output. Unlike coalescence in which the two input segments are fused into one (the features of the two are present in the fused output), in deletion, there is complete loss of the input segment. This is the rationale behind the use of different constraints in the evaluation of harmony in the form of UNIFORMITY-IO and MAX-IO, respectively. 


\begin{tabular}{|c|c|c|c|c|c|c|c|}
\hline 1) $/ \mathrm{N}_{1}-\mathrm{f}_{2} \mathrm{uka} /$ & & a] 'I c & & & & & \\
\hline$/ \mathrm{N}_{1}-\mathrm{f}_{2} \mathrm{uka} /$ & *NCূ & *CODA & $\begin{array}{l}\text { MAX-IO } \\
\text { ROOT }\end{array}$ & "MAX-IO & $\begin{array}{l}\text { IDENT-IO } \\
\text { VOICE }\end{array}$ & $\begin{array}{l}\text { IDENT-IO } \\
\text { NASAL }\end{array}$ & $\begin{array}{l}\text { UNIFOR- } \\
\text { IO }\end{array}$ \\
\hline a. $\otimes \mathrm{f}_{2}$ u.ka & & & & $* !$ & & & \\
\hline b. $\mathrm{n}_{1} \mathrm{f}_{2}$ u.ka & $* !$ & & & & & & \\
\hline c. $\mathrm{N}_{1} \mathrm{f}_{2} \mathrm{u} . \mathrm{ka}$ & & $* !$ & & & & & \\
\hline d. $N_{1}$ u.ka & & & $* !$ & & & & \\
\hline f. $\mathrm{m}^{\mathrm{m}} \mathrm{b}_{12} \mathrm{u} . \mathrm{ka}$ & & & & & $*$ & $*$ & $*$ \\
\hline
\end{tabular}

From the tableau, an incorrect candidate (f) has been declared optimal (back pointing finger) based on the given constraints and ranking. The true optimal candidate should be (a), as shown with a frowning face. However, because the same constraints and ranking resulted in the optimal candidate in the preceding tableau, there is a need to posit one or more constraints. The proposed constraint must be one that is violated by the candidate $\left[{ }^{\mathrm{m}} \mathrm{b}_{12} \mathrm{u} . \mathrm{ka}\right]$ and must be ranked above the one violated by the optimal candidate. The feasible constraints violated by the wrong winner are the lower ranked constraints given in this tableau. Therefore, we invoke the concept of constraint conjunction (Alderete, 1997) in which two low ranked constraints are merged then ranked above the separate members of the pair. If a candidate violates both of them in the same context, a violation mark is incurred. The conjoined constraint is IDENT-IO (voice and nasal).

(22) $/ \mathrm{N}_{1}-\mathrm{f}_{2} \mathrm{uka} / \rightarrow\left[\mathrm{f}_{2} \mathrm{u} . \mathrm{ka}\right]$ 'I cook'

\begin{tabular}{|c|c|c|c|c|c|c|c|c|}
\hline / $/ \mathrm{N}_{1}-\mathrm{f}_{2} \mathrm{uka} /$ & *NC & ${ }^{*} * \mathrm{CODA}$ & $\begin{array}{l}\text { MAX-IO } \\
\text { ROOT }\end{array}$ & $\begin{array}{l}\text { IDENT-IO } \\
\text { voi \& nas }\end{array}$ & MAX-IO & $\begin{array}{l}\text { IDENT- } \\
\text { IO }_{\text {VOICE }}\end{array}$ & $\begin{array}{l}\text { IDENT- } \\
\text { IO }_{\text {NASAL }}\end{array}$ & $\begin{array}{l}\text { UNIF- } \\
\text { IO }\end{array}$ \\
\hline a. $\mathrm{f}_{2} \mathrm{u} . \mathrm{ka}$ & & & & & $* !$ & & & \\
\hline b. $\mathrm{n}_{1} \mathrm{f}_{2} \mathrm{u}$.ka & $* !$ & & & & & & & \\
\hline c. $\mathrm{N}_{1} \mathrm{f}_{2} \mathrm{u} . \mathrm{ka}$ & & $* !$ & & & & & & \\
\hline d. $\mathrm{N}_{1}$ u.ka & & & $* !$ & & & & & \\
\hline f. ${ }^{m} b_{12}$ u.ka & & & & $* !$ & & $*$ & $*$ & $*$ \\
\hline
\end{tabular}

\subsection{No Nasal + Voiced fricative Onset}

As previously reported, the archiphoneme nasal may immediately be followed by a root verb beginning with a voiced bilabial fricative $[\beta]$ forming an unacceptable syllable consonant onset sequence. This sequence normally surfaces as a prenasalized stop rather than a nasal-fricative cluster. Contrary to Pater (1996, 1999, 2001) predictions of *NÇ, the voiced fricative does not emerge intact although it satisfies the markedness constraint * NC. The input prefix nasal assimilates to the place of articulation of the following bilabial fricative resulting in a voiced bilabial prenasalized stop $\left[{ }^{\mathrm{m}} \mathrm{b}\right]$. The process involves two simultaneous phonological processes.

(23) Nasal + voiced fricative onset cluster Input

(i) /N- $\beta$ ala/

$\underset{\mathrm{m}}{\text { Output }}$
[ ba.la]
${ }_{\mathrm{m}}{ }_{\mathrm{m}}$ bo.a $]$
[ be.ka]
[ bi.ra]

Gloss

Repair mechanism

(ii) $/ \mathrm{N}-\beta \mathrm{\beta o} /$

(iii) $/ \mathrm{N}-\beta \mathrm{eka} /$

(iv) $/ \mathrm{N}-\beta i r a /$

$\left.\begin{array}{l}\text { 'I count' } \\ \text { 'I tie' } \\ \text { 'I shave' } \\ \text { 'I pass' }\end{array}\right\}$

Nasal place assimilation and postnasal hardening

The data indicate that the input nasal assimilates to the place of articulation of the following voiced bilabial fricative $[\beta]$. The fricative hardens to a stop [b], but because the language does not have this voiced stop in its phonemic inventory (see table 2 ), the result is a voiced bilabial prenasalized stop [ $\left.{ }^{\mathrm{m}} \mathrm{b}\right]$, that is part of Lubukusu contrastive consonant phonemes.

Pater $(1996,1999,2001)$ had proposed $*$ NC markedness constraint that should penalize inputs with a voiceless obstruent following a nasal. This implies that an input $/ \mathrm{N}_{1}-\beta_{2} \mathrm{eka}$ / should emerge intact because it has a voiced fricative that does not violate the NC constraint. However, without complementary constraints *NC alone is inadequate in determining the optimal candidate form. 
(24) $/ \mathrm{N}_{1}-\beta_{2} \mathrm{eka} / \quad \rightarrow \quad\left[{ }^{\mathrm{m}} \mathrm{b}_{12} \mathrm{e} . \mathrm{ka}\right] \quad$ 'I shave'

\begin{tabular}{|c|c|c|c|c|c|}
\hline$/ \mathrm{N}_{1}-\beta_{2} \mathrm{e} \mathrm{ka} /$ & *NC & ${ }^{*} \mathrm{CODA}$ & MAX-IO & MAX-IO & UNIFOR-IO \\
\hline a. $\otimes\left[{ }^{\mathrm{m}} \mathrm{b}_{12} \mathrm{e} \cdot \mathrm{ka}\right]$ & & & & & $*$ \\
\hline b. $\left[\mathrm{m}_{1} \beta_{2} \mathrm{e} . \mathrm{ka}\right]$ & & & & & \\
\hline c. $\left[\mathrm{m}_{1} \cdot \beta_{2} \mathrm{e} \cdot \mathrm{ka}\right]$ & & $* !$ & & & \\
\hline d. $\left[\mathrm{m}_{1}\right.$ e.ka] & & & $* !$ & & \\
\hline e. $[\beta \mathrm{e} . \mathrm{ka}]$ & & & & $* !$ & \\
\hline
\end{tabular}

Candidate (b) is assessed to be optimal based on these constraints and the ranking, yet it is unattested in the language. The current result implies free variation between candidates (a) and (b) in the phonology of Lubukusu, however, this is not the case. Candidate (a) is the only candidate known to be the attested output of the given input. The *NC constraint is inadequate when the input fricative is specified as [+voice], the feature that is being evaluated There is need for another constraint; SSP to work together with *NÇ for a felicitous evaluation of outputs.

$(25) / \mathrm{N}_{1}-\beta_{2} \mathrm{eka} / \quad \rightarrow \quad\left[{ }^{\mathrm{m}} \mathrm{b}_{12} \mathrm{e} . \mathrm{ka}\right] \quad$ 'I shave'

\begin{tabular}{|l|l|l|}
\hline \hline $\mathrm{N}_{1}-\beta_{2} \mathrm{eka} /$ & ${ }^{\mathrm{N} C}$ & SSP \\
\hline a. ${ }^{\mathrm{m}}\left[{ }^{\mathrm{m}} \mathrm{b}_{12} \mathrm{e} . \mathrm{ka}\right]$ & & \\
\hline b. $\left[\mathrm{m}_{1} \beta_{2} \mathrm{e} . \mathrm{ka}\right]$ & & $* !$ \\
\hline
\end{tabular}

From the tableau, it is clear that a nasal-voiced fricative sequence does not violate the *NÇ constraint, but, because it has a sonority reversal, it violates SSP. In the following tableau, more candidates are added including those with a syllabic nasal. A markedness constraint against consonantal nucleus ([*PEAK-C]) is included.

(26) $/ \mathrm{N}_{1}-\beta_{2} \mathrm{eka} / \quad \rightarrow \quad\left[{ }^{\mathrm{m}} \mathrm{b}_{12} \mathrm{e} . \mathrm{ka}\right] \quad$ 'I shave'

\begin{tabular}{|l|l|l|l|l|l||}
\hline$/ \mathrm{N}_{1}-\beta_{2} \mathrm{eka} /$ & *NC & SSP & MAX-IO ${ }_{\text {ROOT }}$ & MAX-IO & *PEAK-C \\
\hline \hline a. ${ }^{\mathrm{m}}{ }^{\mathrm{m}} \mathrm{b}_{12} \mathrm{e}$.ka] & & & & & \\
\hline b. $\left[\mathrm{m}_{1} \beta_{2} \mathrm{e} \cdot \mathrm{ka}\right]$ & & $* !$ & & & \\
\hline c. $\left[\mathrm{m}_{1} \mathrm{e} . \mathrm{ka}\right]$ & & $* !$ & & \\
\hline d. $\left[\mathrm{b}_{2} \mathrm{e} . \mathrm{ka}\right]$ & & & $* !$ & & \\
\hline e. $\left[\mathrm{m}_{1} \cdot \mathrm{b}_{2} \mathrm{e}\right.$ e.ka] & & & $*$ & & $* !$ \\
\hline
\end{tabular}

The results confirm the fact that $*$ NC alone cannot produce the actual optimal candidate of the language, instead, there is need for the sonority constraint to disqualify candidate (b). Without *PEAK-C, candidate (e) could have been optimal in addition to (a). In the following tableau, all the constraints proposed are incorporated into the tableau to show their interaction and if they yield one single optimal candidate. However, because * $\mathrm{NC}$ is not violated in any of the candidates, it can be omitted without any cost on the efficacy of the analysis.

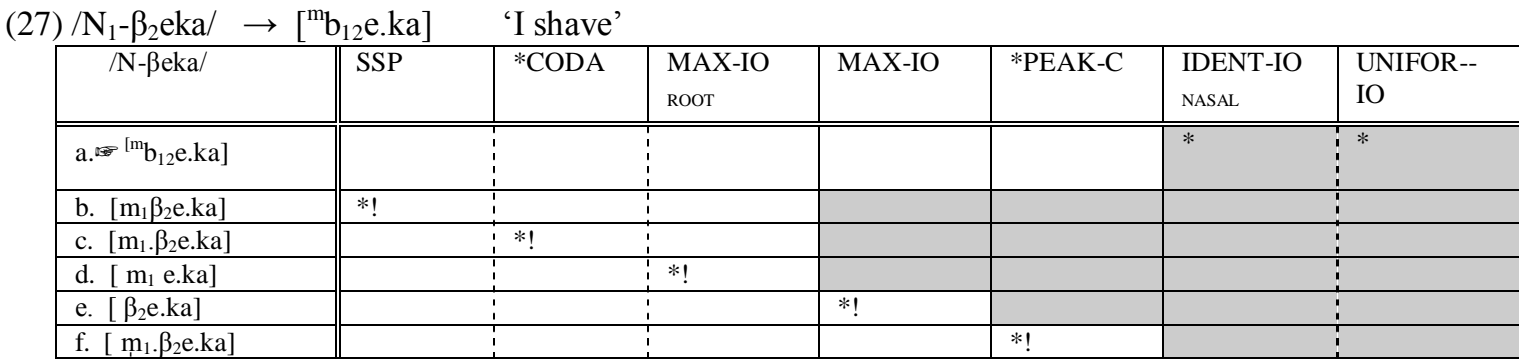

Thus far, the tableau gives the right optimal candidate based on the ranking from the previous analysis. Note that a cluster of a nasal and a fricative is marked from the articulatory point of view. This is because OT constraints have a phonetic grounding; they state facts about the language, facts that can be accounted for from articulatory limitations, acoustic experimentation or perceptual distinctiveness. In this regard, production of such a cluster is against the concept of ease of articulation because a cluster involves gestural overlap between the two segments (Browman \& Goldstein, 2000; Byrd, 1992). Maintaining a nasal gesture that demands a complete velopharyngeal closure and a fricative gesture that requires an oral airstream passage are at odds with each other. Because of the need to synchronize articulations, this demands more articulatory effort and, therefore, not 
preferred leading to their marked status. Undominated markedness constraints forbid such sequences as a result (Flemming, 1995).

\subsection{No Nasal + Liquid Onset Cluster}

Lubukusu does not tolerate an onset cluster of nasal-liquid sequence. The sequence is repaired taking on the homorganic voiced alveolar prenasalized stop $\left[{ }^{\mathrm{n}} \mathrm{d}\right]$; the liquid is an alveolar sound.

(28) Nasal + Liquid onset cluster

$\left.\begin{array}{lll}\text { Input } & \text { Output } & \text { Gloss } \\ / \mathrm{N}_{1}-\mathrm{l}_{2} \text { ima/ } & {\left[{ }^{\mathrm{n}} \mathrm{d}_{12} \text { i.ma }\right]} & \text { 'I dig' } \\ / \mathrm{N}_{1}-\mathrm{l}_{2} \text { oma/ } & {\left[{ }^{\mathrm{n}} \mathrm{d}_{12} \mathrm{O} . \mathrm{ma}\right]} & \text { 'I speak' } \\ / \mathrm{N}_{1}-\mathrm{r}_{2} \mathrm{ura} / & {\left[{ }^{\mathrm{n}} \mathrm{d}_{12} \text { u.ra }\right]} & \text { 'I depart' } \\ / \mathrm{N}_{1}-\mathrm{r}_{2} \mathrm{ema} / & {\left[{ }^{\mathrm{n}} \mathrm{d}_{12} \text { e.ma }\right]} & \text { 'I cut' }\end{array}\right\} \begin{aligned} & \text { Repair mechanism } \\ & \begin{array}{l}\text { Nasal place assimilation } \\ \text { and post-nasal hardening }\end{array}\end{aligned}$

An examination of the data indicates that no nasal can be followed by a liquid whether it is the voiced alveolar lateral or the voiced alveolar trill. Phonetically, this may because the two sounds (nasal-liquid) are sonorants; they require spontaneous voicing for an extended period of time. This is in contradiction of the ease of articulation principles that govern the sequencing of consonants in cluster. Nasal production requires complete velum closure while liquids requires oral escape of the airstream (lateral passage). Onset cluster are produced with a substantial degree of gestural overlap, therefore, synchronizing the two processes is more effortful and practically impossible. In terms of ease of articulation, it is easier to articulate a stop with superimposed pre-nasalization than simultaneous two full-fledged nasal and oral sounds.

Formal establishment of the OT constraints responsible for the repair mechanism requires reference to the markedness scale. The onset cluster markedness scale (9) show that ${ }^{*} \mathrm{CL}$ (*NL in this analysis) is an undominated constraint that bans any consonant sequence except the ${ }^{*} \mathrm{CG}\left({ }^{*} \mathrm{NG}\right)$. Based on the markedness scale of possible onset clusters in the language, it is unlikely for a cluster of the form CL (*NL) to be harmonic because the Lubukusu ranking puts ${ }^{*} \mathrm{CL}$ above $* \mathrm{CG}$ in increasing markedness $(* \mathrm{CL} \gg * \mathrm{CG}$ or $* \mathrm{CG}>* \mathrm{CL}$ ) and ${ }^{*} \mathrm{CL}$ is undominated. An OT analysis depends fully on constraint interaction and those developed up to this point should suffice. The *NÇ constraint will be used to evaluate the harmony of this sequence as proposed by Pater (1996, 1999, 2001). This is based on the assumption that such a sequence should be licit because the liquid is voiced. Second, some faithfulness constraints that penalize cluster coalescence into a prenasalized stop [ ${ }^{\mathrm{n}} \mathrm{d}$ ] should be included in the hierarchy. Finally, constraints that demand input features and segments to have correspondents in the output are included. The liquid has the feature [+son], for 'sonorant' while the nasal has the nasality feature [+nasal]. UNIFORMITY-IO is relevant in assessing the coalescence of the two sounds.

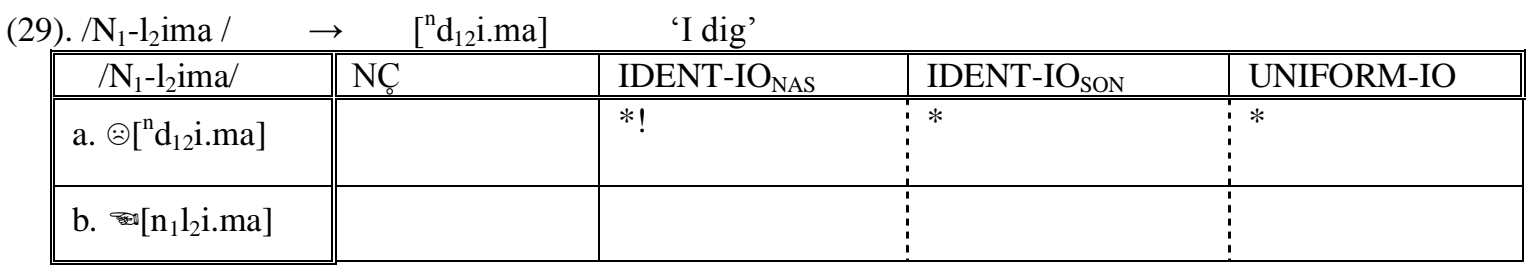

The NC constraint without other markedness constraint cannot yield the exp ected optimal candidate. The candidate selected as optimal is an incorrect one because candidate (b) has a marked onset cluster: CL. A

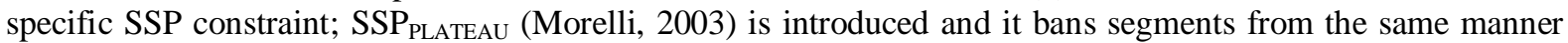
class in an onset cluster. Therefore, two sonorants (nasal and liquid) cannot constitute an onset cluster; they form a sonority plateau. This may explain the phonological gap or the absence of [ww], [jw] and [jj] and [wj] in the onset cluster inventory of the language although they fit the ${ }^{*} \mathrm{CG}$ sequence requirement.

\begin{tabular}{|c|c|c|c|c|c|c|c|}
\hline 30). $/ \mathrm{N}_{1}-\mathrm{l}_{2} \mathrm{ima} /$ & $\rightarrow$ & [ ${ }^{\mathrm{n}} \mathrm{d}_{12}$ i.ma] & 'I dig' & & & & \\
\hline$/ \mathrm{N}_{1}-\mathrm{l}_{2} \mathrm{ima} /$ & "NCূ & SSPPLATEAU & $\begin{array}{l}\text { MAX-IO } \\
\text { ROOT }\end{array}$ & "MAX-IO & *PEAK-C & $\begin{array}{l}\text { IDENT- } \\
\text { IO }_{\text {NAS }}\end{array}$ & $\begin{array}{l}\text { IDENT- } \\
\text { IO }_{\text {SON }}\end{array}$ \\
\hline a. $\left[{ }^{n} d_{12}\right.$ i.ma $]$ & & & & & & * & * \\
\hline b. $\left[\mathrm{n}_{1} \mathrm{l}_{2} \mathrm{i} . \mathrm{ma}\right]$ & & $* !$ & & & & & \\
\hline c. $\left[\mathrm{n}_{1}\right.$ ima $]$ & & 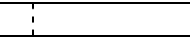 & $* !$ & & & & \\
\hline d. $\left[1_{2}\right.$ i.ma $]$ & & 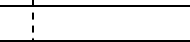 & & $* !$ & & & \\
\hline e. [n.l. $l_{2}$ i.ma ] & & 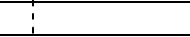 & & & $* !$ & & \\
\hline
\end{tabular}


The optimal candidate is the true attested form in the language; neither deletion nor insertion of segments produces an acceptable onset. Formation of syllabic nasal is not justified by the context and the markedness constraint against syllabic consonants (*PEAK-C) ensures this does not happen if ranked above the constraint(s) violated by the optimal candidate. As a class, the sonorants in (b) display a sonority plateau based on sonority distance theory of syllabification (Baertsch, 1998; Gouskova, 2004), the sonority distance between them is minimal.

The inclusion of $* \mathrm{NC}$ may seem redundant but it is meant to capture the fact that the ranking is fixed but above all, to ensure the input root sonorants are not changed into voiceless stops in the outputs. Note that given the input $/ \mathrm{N}_{1}-\mathrm{l}_{2} \mathrm{ima} /$, the generator function GEN can produce $\left[\mathrm{n}_{1}-\mathrm{t}_{2} \mathrm{ima}\right.$ ] output as one of the limitless possible candidates. Ultimately, it is the top ranked *NC that will take care of this candidate (f, below) by ensuring such a cluster is rendered sub-optimal.

(31). $/ \mathrm{N}_{1}-\mathrm{l}_{2}$ ima $/ \rightarrow\left[{ }^{\mathrm{n}} \mathrm{d}_{12}\right.$ i.ma $] \quad$ 'I dig'

\begin{tabular}{|c|c|c|c|c|c|c|c|}
\hline$/ \mathrm{N}_{1}-\mathrm{l}_{2} \mathrm{ima} /$ & *NÇ & SSP Plateau & $\begin{array}{l}\text { MAX-IO } \\
\text { RоOт }\end{array}$ & MAX-IO & PEAK-C & $\begin{array}{l}\text { IDENT- } \\
\text { IO }_{\text {NAS }}\end{array}$ & $\begin{array}{l}\text { IDENT- } \\
\text { IO }_{\text {SON }}\end{array}$ \\
\hline a. $\left[{ }^{\mathrm{n}} \mathrm{d}_{12} \mathrm{i} . \mathrm{ma}\right]$ & & & & & & $*$ & * \\
\hline b. $\left[\mathrm{n}_{1} \mathrm{l}_{2} \mathrm{i} . \mathrm{ma}\right]$ & & $* !$ & & & & & \\
\hline c. $\left[\mathrm{n}_{1}\right.$ i.ma $]$ & & & $* !$ & & & & \\
\hline d. $\left[1_{2}\right.$ i.ma $]$ & & & & $* !$ & & & \\
\hline e. [n.l. li.ma & & & & & $* !$ & & \\
\hline f. $\left[\mathrm{n}_{1} \mathrm{t}_{2}\right.$ i.ma $]$ & $* !$ & & & & & & $*$ \\
\hline
\end{tabular}

The fact that candidate ( $\mathrm{f}$ ) is disqualified by the *NC constraint is vital especially from the ranking point of view. If this constraint is not included in the constraint hierarchy, the result would be unacceptable because this sub-optimal candidate would in fact emerge the winner based on this ranking without the

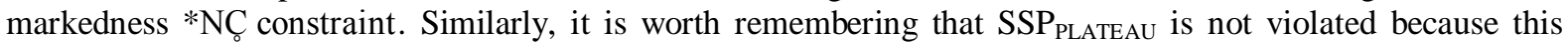
constraint only punishes clusters with a sonority plateau and not a sonority reversal. A nasal-plosive sequence

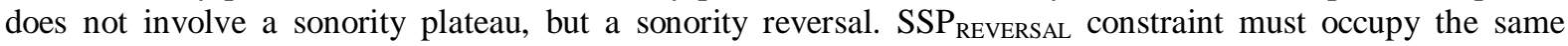
position occupied by the *NÇ; it must be undominated in the hierarchy. Note that the same result will be obtained based on same constraints and ranking for the input $/ \mathrm{N}_{1}-\mathrm{r}_{2} \mathrm{ura} /$. We now examine the final type of $* \mathrm{NC}$ effects the: $/ \mathrm{N}+\mathrm{N} /$; part of the $\mathrm{NC}$ et cluster typology.

\subsection{No Nasal + Nasal Onset Cluster}

In the discussion of the syllable structure typology of the Lubukusu language, it was observed that the nasal is the only consonant that can act as a syllabic consonant. In addition, besides the CG, no other onset cluster can be optimal. On the basis of these facts, it follows that a sequence of a nasal-nasal in the syllable onset is marked.

(32) Syllabic nasals arising from *NN effects.

\section{Prefix 'I'+ stem Surface form}

(a) /N-nula/

(b) /N-mala/

(c) /N-nala/

(d) /N-nona/

$\begin{array}{ll}\text { Surface form } & \text { English gloss } \\ \text { [n.nu.la] } & \text { 'I get sweet' } \\ \text { [m.ma.la] } & \text { 'I complete' } \\ \text { [n..na.la] } & \text { 'I can/am able' } \\ \text { [y.yo.na] } & \text { 'I make' }\end{array}$

Predictably, the data indicate that a nasal-nasal sequence is a marked onset cluster and the repair strategy adopted is the promotion of the initial nasal in the sequence to a syllabic consonant. The result is a syllable formed from the prefix nasal. The markedness associated with such a sequence is based on sonority; two nasals in the onset position form a sonority plateau in having equal sonority index. Ideally, sonority should rise from the initial consonant in the onset cluster to the next up to the peak. This requirement forces the initial nasal to separate into a distinct syllable thus forming a syllabic segment. Formation of syllabic consonants is in violation of the constraint against consonantal nucleus: *PEAK-C. The sonority constraint, SSP PLATEAU should dominate *PEAK-C.

\begin{tabular}{|c|c|c|}
\hline$/ \mathrm{N}_{1}-\mathrm{n}_{2}$ ula/ & {$\left[\mathrm{n}_{1} \cdot \mathrm{n}_{2} \mathrm{u} . \mathrm{la}\right]$ 'I get sweet' } & \\
\hline / $/ \mathrm{N}_{1}-\mathrm{n}_{2} \mathrm{ula} /$ & $\begin{array}{l}\text { SSP Plateau } \\
\end{array}$ & *PEAK-C \\
\hline a. $\left[n_{1} \cdot n_{2}\right.$ u.la $]$ & & $*$ \\
\hline b. $\quad\left[n_{1} n_{2}\right.$ u.la] & $* !$ & \\
\hline
\end{tabular}


In the tableau, candidate (a) that has transformed the initial nasal into syllabic peak position is optimal but not candidate (b) because the two nasals form an unacceptable onset. Such an onset violates the sonority sequencing requirement that onset cluster segments must differ in their sonority index to the extent that the preonset has lower sonority than the onset segment. Also a markedness constraint, OCP demands that adjacent segments are not similar in some phonological features banning a $/ \mathrm{N}+\mathrm{N} /$ onset sequence and the promotion of initial nasal to syllable nucleus. OCP is generally not violated in the language and this may explain why there are no $/ \mathrm{nn} /$ sequences, or geminates in Lubukusu. OCP has to be ranked above *PEAK-C just like SSP PLATEAU so that it is less costly to violates *PEAK-C.

However, as seen from the discussion of other $* \mathrm{NC}$ effects, there are other possible ways of avoiding the violation of $* \mathrm{NN}$ in Lubukusu language, however, these other options are not adopted by the grammar. There must be some constraints that prohibit such possibilities from being realized. Marked clusters could be broken by insertion of a vowel between the two nasals; however, DEP-IO is responsible for the failure to use vowel epenthesis. Deletion of one of the nasals could result in an acceptable onset of the CV form, but the

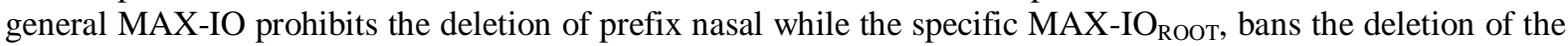
root nasal. These three constraints interacting with others are responsible for the formation of the syllabic nasals rather than nasal deletion or vowel insertion; they must be ranked above the *PEAK-C.

(34) $/ \mathrm{N}_{1}-\mathrm{n}_{2} \mathrm{ula} / \quad \rightarrow \quad\left[\mathrm{n}_{1} \cdot \mathrm{n}_{2} \mathrm{u}\right.$.la] $\quad \rightarrow \quad$ get sweet'

\begin{tabular}{||l||l|l|l|l|l||}
\hline \hline$/ \mathrm{N}_{1}-\mathrm{n}_{2}$ ula & OCP & MAX-IO & MOOT & DEX-IO & *PEAK-C \\
\hline \hline a. $\left[\mathrm{n}_{1} \cdot \mathrm{n}_{2} \mathrm{u} . \mathrm{la}\right]$ & & & & \\
\hline b. $\left[\mathrm{n}_{1} \mathrm{n}_{2} \mathrm{u} . \mathrm{la}\right]$ & $* !$ & & & & \\
\hline c. $\left[\mathrm{n}_{1} \mathrm{u} . \mathrm{la}\right]$ & & $* !$ & & & \\
\hline d. $\left[\mathrm{n}_{2} \mathrm{u}\right.$.la] & & $* !$ & & \\
\hline e. $\left[\mathrm{n}_{1}\right.$ i. $\left.\mathrm{n}_{2} \mathrm{u} . \mathrm{la}\right]$ & & & $* !$ & \\
\hline
\end{tabular}

There is still one more possible candidate that ought to be included in the tableau based on ROTB concept. The possible candidate is one that actually merges the two nasals into one. It was reported that formation of a prenasal involves coalescence which is essentially a merger or fusion of the two sounds. The constraint that forbids this kind of merger is the UNIFORMITY-IO.

\begin{tabular}{|c|c|c|c|c|c|c|}
\hline$/ \mathrm{N}_{1}-\mathrm{n}_{2} \mathrm{ula} /$ & & $\left.\mathrm{n}_{2} \mathrm{u} . \mathrm{la}\right]$ & et sweet' & & & \\
\hline $\bar{~} / \mathrm{N}_{1}-\mathrm{n}_{2} \mathrm{ula} /$ & $\overline{\mathrm{OCP}}$ & 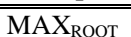 & MAX-IO & DEP-IO & *PEAK-C & UNIFOR-IO \\
\hline $\mathrm{a} \cdot \odot\left[\mathrm{n} \cdot \mathrm{n}_{2} \mathrm{u} \cdot \mathrm{la}\right]$ & & & & & $* !$ & \\
\hline b. $\quad\left[\mathrm{n}_{1} \mathrm{n}_{2} \mathrm{u} . \mathrm{la}\right]$ & $* !$ & & & & & \\
\hline c. [n $\mathrm{n}_{1}$ u.la] & & $* !$ & & & & \\
\hline d. [n & & & $* !$ & & & \\
\hline e. $\left[\mathrm{n}_{1}\right.$ i.n. $\mathrm{n}_{2}$ u.la] & & & & $* !$ & & \\
\hline f. $\left[n_{12}\right.$ u.la] & & & & & & * \\
\hline
\end{tabular}

The winning candidate is not the optimal one attested in Lubukusu. This anomaly indicates that there is need to introduce a constraint that is actually violated by candidate (f) but satisfied by the true optimal candidate. In (f), the input morphemes have been merged into one: two input morphemes have been mapped onto one morpheme in the output. The constraint requiring that every input morpheme is realized by some phonological output material is REALIZE-MORPHEME, in short, REAL-MORPH (Kurisu, 2001; Trommer, 2009). This constraint is not violated in prenasals. The constraint; REALIZE-MORPHEME, states that for every morpheme in the input, some phonological element should be present in the output. Because this candidate already violates the UNIFORMITY-IO, it will be appropriate to rank REAL-MORPH together with *PEAK-C..

\begin{tabular}{|c|c|c|c|c|c|c|c|}
\hline 36) $/ \mathrm{N}_{1}-\mathrm{n}_{2} \mathrm{ula} /$ & $\rightarrow$ & {$\left[\mathrm{n}_{1} \cdot \mathrm{n}_{2} \mathrm{u} . \mathrm{la}\right]$} & 'I get swe & & & & \\
\hline$/ \mathrm{N}_{1}-\mathrm{n}_{2} \mathrm{ula} /$ & \begin{tabular}{|l} 
OCP \\
\end{tabular} & $\begin{array}{l}\text { MAX- } \\
\text { IO }_{\text {ROOT }}\end{array}$ & MAX-IO & DEP-IO & $\begin{array}{l}\text { REAL- } \\
\text { MORPH }\end{array}$ & *PEAK-C & UNIFOR-IO \\
\hline $\mathrm{a} \cdot\left[\mathrm{n}_{1}, \mathrm{n}_{2} \mathrm{u} . \mathrm{la}\right]$ & & & & & & * & \\
\hline b. $\left[\mathrm{nn}_{1} \mathrm{n}_{2} \mathrm{u} . \mathrm{la}\right]$ & $* !$ & 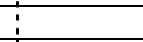 & & & & & \\
\hline c. [n $n_{1}$ u.la] & & $* !$ & & & & & \\
\hline d. [n $\left.\mathrm{n}_{2} \mathrm{u} . \mathrm{la}\right]$ & & & $* !$ & & & & \\
\hline e. $\left[\mathrm{n}_{1}\right.$ i. $\left.\mathrm{n}_{2} \mathrm{u} . \mathrm{la}\right]$ & & 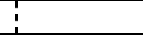 & & $* !$ & & & \\
\hline f. $\left[\mathrm{n}_{12} \mathrm{u} .1 \mathrm{la}\right]$ & & 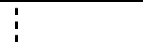 & & & $*$ & & $* !$ \\
\hline
\end{tabular}


The language prefers that the $1^{\text {st }}$ person prefix nasal morpheme is realized in some way rather than being deleted or merged. This results in the formation of a syllabic nasal which maintains the status of the morpheme in some phonological form. This differentiates the optimal candidate (a) from (f) which is suboptimal because of fusing the first person prefix and root morphemes. So far, the constraints can indeed account for the various *NC effects observed in Lubukusu through language specific ranking of universal constraints. In addition, the syllable structure of the language is a central constraining force that drives the various forms of *NC effects exhibited in the language. This confirms prediction from the typology of * NC effects and onset clusters.

\subsection{The Optimal Nasal + Glide Onset}

Having established that the constraints proposed and their ranking can yield the optimal forms, there is need to determine how the same constraints can account for the only cluster allowed in the onset position in a nasal-consonant cluster; the NG sequence. The cluster falls under the *NC effects but it is unique in being permissible.

(37) The permissible CG (NG) onset cluster.

Input Output

(a) $/ \mathrm{N}_{1}-\mathrm{j}_{2} \mathrm{uxa} /$

(b) $/ \mathrm{N}_{1}-\mathrm{j}_{2} \mathrm{esja} /$

(c) $/ \mathrm{m}_{1} \mathrm{u}_{2}$-ana/

(d) $/ \mathrm{m}_{1} \mathrm{u}_{2}$-ica/

\section{$\left[\mathrm{n}_{1} \mathrm{j}_{2} \mathrm{u} . \mathrm{xa}\right]$}

$\left[\mathrm{n}_{1} \mathrm{j}_{2} \mathrm{e} . \mathrm{sja}\right]$

[ $\mathrm{m}_{1} \mathrm{w}_{2} \mathrm{a}:$.na]

$\left[\mathrm{m}_{1} \mathrm{w}_{2} \mathrm{i}: . \mathrm{ca}\right]$
English gloss

'I return'

'I bend (something)'

'you scream'

'you come'

The same constraints that were used in the evaluation of other *NC effects shall be employed in analyzing these data. To begin with, it is shown that the general * $\mathrm{CC}(* \mathrm{NC})$ as proposed by Archangeli et al., (1998) to replace Pater's (1996) * NC cannot produce the optimal candidate with any cluster. In fact, without another top-ranked constraint set, ${ }^{*} \mathrm{CC}$ alone will rule out any onset cluster including the legitimate NG onset sequence.

(38) $/ \mathrm{N}_{1}-\mathrm{j}_{2} \mathrm{uxa} / \rightarrow \quad\left[\mathrm{n}_{1} \mathrm{j}_{2} \mathrm{u} . \mathrm{xa}\right] \quad$ 'I return'

\begin{tabular}{|c|c|c|c|c|c|c|}
\hline$/ \mathrm{N}_{1}-\mathrm{j}_{2} \mathrm{uxa} /$ & $* \mathrm{CC}$ & SSP & MAX-воот & MAX-IO & DEP-IO & *PEAK-C \\
\hline a. ${ }^{\otimes}\left[\mathrm{n}_{1} \mathrm{j}_{2}\right.$ u.xa $]$ & $* !$ & & & & & \\
\hline b. [n $n_{1}$ u.xa] & & & $* !$ & & & \\
\hline c. $\left[\mathrm{j}_{2} \mathrm{u} . \mathrm{xa}\right]$ & & & & $* !$ & & \\
\hline d. [ni. ij $\left._{2} \mathrm{u} . \mathrm{xa}\right]$ & & & & & $* !$ & \\
\hline e. $\quad\left[n_{1} j_{2} u . x a\right]$ & & & & & & $*$ \\
\hline
\end{tabular}

The constraint, $* \mathrm{CC}$, is not relevant for this language, instead, *NC, SSP and OCP, as undominated constraints can handle all $* \mathrm{NC}$ effects. If we omit this constraint from the tableau and introduce the specific *NC that prohibits nasalobstruent sequence, the result is satisfactory.

$(40) / \mathrm{N}_{1}-\mathrm{j}_{2} \mathrm{uxa} / \rightarrow\left[\mathrm{n}_{1} \mathrm{j}_{2} \mathrm{u} . \mathrm{xa}\right] \quad$ 'I return'

\begin{tabular}{|c|c|c|c|c|c|c|}
\hline$/ \mathrm{N}_{1}-\mathrm{j}_{2} \mathrm{uxa} /$ & $* \mathrm{NC}$ & SSP & MAX-ROOT & MAX-IO & DEP-IO & *PEAK-C \\
\hline a. $\left[\mathrm{n}_{1} \mathrm{j}_{2} \mathrm{u} . \mathrm{xa}\right]$ & & & & & & \\
\hline b. $\left[n_{1}\right.$ u.xa] & & & $* !$ & & & \\
\hline c. $\left[\mathrm{j}_{2} \mathrm{u} \cdot \mathrm{xa}\right]$ & & & & $* !$ & & \\
\hline d. [ni. ${ }_{1} \mathrm{j}_{2}$ u.xa] & & & & & $* !$ & \\
\hline e. $\left[\mathrm{n}_{1} \mathrm{j}_{2} \mathrm{u} . \mathrm{xa}\right]$ & & & & & & $*$ \\
\hline
\end{tabular}

The tableau confirms the argument that the general $* \mathrm{CC}(* \mathrm{NC})$ is not appropriate for this language and that a nasal-glide sequence is the only optimal cluster in the onset of a syllable in Lubukusu. It is also fundamental that we are able to account for all the $* \mathrm{NC}$ effects in one language based on the fixed ranking of some universal constraints. One of the basic tenets of OT is that in one language, constraint accounting for syllable structure, for instance, cannot vary in the hierarchy. In the analysis, it is clear that the constraints established for the nasal-obstruent sequence, for instance, maintain their ranking in the rest of the analysis. Even in cases where the constraint is not relevant, it is assumed that it keeps its position in the hierarchy though invisible. 


\section{The Failure Of The Rule-Based Vis-À-Vis Ot Account}

The most important implication from the entire analysis pertains to what phonologists in the traditional rule-based analysis referred to as 'the duplication problem' and 'the conspiracies'. The first of these terms refers to an instance in which different phonological rules were posited to account for a single target in different environments within a language, or in different languages (Kenstowicz \& Kisseberth, 1977). Second, conspiracies refers to cases in which phonological rules seem to 'conspire' against a marked structure in a language. In this case, the different rules that were invoked to block a sequence of a nasal and a voiceless obstruent were said to 'conspire' against such an onset cluster. In OT, the duplication problems is avoided through a single constraint hierarchy for all $* \mathrm{NC}$ onset clusters. There is no need to posit different rules to account for the markedness of a $* \mathrm{NC}$ sequences (no duplication of rules).

In OT, the duplication problem and conspiracies have been dubbed 'the homogeneity of target and the heterogeneity of process' McCarthy, 2002; Pater, 1999). This refers to a single target (a requirement or prohibition) being achieved through different mechanisms (processes). This is a basic typological claim of OT as a surface-oriented theory; same output forms may be achieved through different ways across languages or even within the same language. In this analysis of $* \mathrm{NC}$ effects in Lubukusu, it has been observed that a single markedness (*NC cluster-here referred to as the homogeneity of target) is resolved through different mechanisms; the different repair strategies of nasal assimilation, post-nasal hardening and voicing, nasal deletion and formation of syllabic nasals.

Depending on contexts, it has been observed that the markedness of NC onset cluster is avoided through different repair strategies depending on the phonological properties of the following root consonant. This is conveniently achieved through the interaction of markedness and faithfulness constraints. There is no need to duplicate rules for the same target or the invoking of external evidence for the different processes targeting the $* \mathrm{NC}$ clusters. Unlike rules that end up producing the same or a different marked structures (because they are blind to the output), the surface-oriented OT does not have this shortcoming. Once the markedness constraints are identified and ranked appropriately above the faithfulness constraints, the optimal candidate is guaranteed to emerge; a structure that is unmarked based on the language's constraint hierarchy.

In essence, markedness constraints suitably ranked is responsible for the absence of any nasalconsonant sequence except the optimal nasal-glide (NG) sequence in the syllabic onset position of Lubukusu. It has been reported that cases of process heterogeneity are clear in conspiracies so that even within the same language they surface. For example in Lubukusu, the same markedness constraint; *NC, may be satisfied in different ways (nasal place assimilation, post-nasal voicing or deletion) depending on context (a nasal-consonant sequence involved). For this type of process heterogeneity to occur , the markedness constraint (*NÇ) must

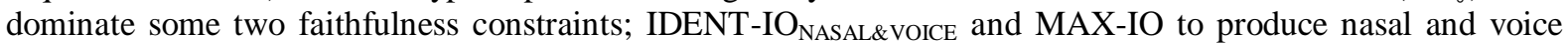
assimilation on one hand, and deletion on the other. McCarthy (2002:93-5) argues that the heterogeneity of a process can occur in a single language as shown in this study. The *NC markedness has been avoided differently depending on the phonological contexts.

Unlike rule ordering which is often contradictory in accounting for simultaneous processes such as nasal assimilation and post-nasal voicing, OT avoids this problem because candidates are evaluated globally in parallel, with no serialism or ordered evaluation. Rule ordering cannot account for whether nasal place assimilation takes place before the voicing of the following obstruent or vice versa. Rule ordering gives the false assumption that one of these processes can take place independent of the other, yet such a possibility does not exist. This justifies the parallel and global approach in OT in which the two processes of nasal assimilation and post-nasal voicing take place simultaneously. OT analysis is parallel in that GEN respects inclusivity and freedom of analysis; it emits candidates that may vary from the input in various ways. In terms of its globality, OT's EVAL takes a single language particular hierarchy ' $\mathrm{H}$ ' then subjects it to the entire candidate set from the input. In other words, the entire candidate chain is evaluated by the hierarchy in terms of all of its wellformedness and faithfulness aspects.

In conclusion, the universal constraints ranked in a language-particular hierarchy can adequately account for the harmonic status of CG clusters and the prohibition of other types of onset cluster in Lubukusu. The markedness constraints demand syllable well-formedness on the outputs so that marked onsets such as those violating SSP are banned in the outputs. On the other hand, faithfulness constraints demand faithful mapping of input to surface forms (the outputs) ensure that input form of CG clusters are parsed faithfully on the surface. It is the contradicting demands of the markedness constraints demanding well-formed syllables (may demand change to attain it) interacting with faithfulness constraints (militate against change), that is responsible for the violable nature of constraints. Some syllables are unmarked $(\mathrm{CV})$ while others have clusters $(\mathrm{CCV})$ all resulting from the interaction between the opposing constraints. This is at the core of this study, that constraint interaction is the basis for the observed syllable structure and the ensuing *NC effects that are clearly constrained by this structure. This is important because in OT, there is no other way that the grammar of a language can be accounted for, except by constraint interaction based on a language-particular ranking of universal constraints. 


\section{References}

[1]. Alderete, J. (1997). Dissimilation as local conjunction. In K. Kusimoto (Ed.), Proceedings of NELS 27, Amherst, MA: GLSA.

[2]. Archangeli, D. \& Langendoen, T. (1996). Optimality Theory: An overview. Oxford: Blackwell.

[3]. Archangeli, D., Moll, L., \& Ohno, K. (1998). Why not *NC.. Chicago: Chicago Linguistic Society, 34,1-26.

[4]. Baertsch, K. (1998). Onset sonority distance constraints through local conjunction. Chicago Linguistic Society, $34,2,1-16$.

[5]. Beckman, J. N. (1999). Positional faithfulness: An Optimality theoretic treatment of phonological asymmetries. New York: Rutledge.

[6]. Bell-Berti, F. (1993). Understanding velic motor control: Studies of segmental context. In Marie, K. H \& Rena K (Eds.). Nasals, Nasalization and the Velum 63-85. San Diego: AP.

[7]. Blevins, J. (1995). The syllable in phonological theory. In J. Goldsmith (Ed.), The handbook of phonological theory. Cambridge Mass: Blackwell.

[8]. Browman, C. P \& Goldstein, L. (1990). Gestural specification using dynamically-defined articulatory structures. Journal of Phonetics, 18, 299-320.

[9]. Browman, C. P \& Goldstein, L. (2000). Competing constraints on intergestural coordination and self-organization of phonological structures.

[10]. Bulletin de la Communication Parlée, 5, 25-34.

[11]. Byrd, D. (1992). Perception of assimilation in consonantal clusters: A gestural model. Phonetica, $49,1-24$.

[12]. Byrd, D \& Choi, S. (2009). At the juncture of prosody, phonology and phonetics: The interaction of phrasal and syllable structure in shaping the timing of consonantal gesture. Laboratory Phonology 10.

[13]. Cairns, E, C \& Reimy, E. (2011). Handbook of the syllable. Leiden: Brill.

[14]. Chotoran, I., Goldstein L. \& Byrd, D. (2002). Gestural overlap and recoverability: Articulatory evidence from Georgian. In C. Gussenhoven \& E. Warner (Eds.), Laboratory Phonology 7: 419-448.

[15]. de Lacy, P. (2004). Markedness conflation in Optimality theory. Cambridge: Cambridge University Press.

[16]. Demolin, D. (2007). Coarticulatory timing and aerodynamics of nasals and nasalization. Proceedings of international conference on phonetic science XVI.

[17]. Downing, L. J. (2006). Canonical forms in prosodic morphology. Oxford: Oxford University Press.

[18]. Durand, J. (1994). Generative and Non-linear phonology. London: Longman Group.

[19]. Flemming, E. (1995). Auditory representations in phonology. PhD dissertation. University of California, Los Angeles.

[20]. Flemming, E. (2004). Contrast and perceptual distinctiveness. In B. Hayes, D. Steriade \& R. Kachner. (Eds.), Phonetically-based phonology. New York: CUP.

[21]. Goldsmith, J (2011). The syllable. In J. Goldsmith, J. Riggle \& L. C. Yu (Eds.), The handbook of phonological theory (2 ${ }^{\text {nd }}$ ed.), Malden MA: Blackwell.

[22]. Gouskova, M. (2004). Relational hierarchies in Optimality Theory: The case of syllable contact. Phonology, 21:2, 201-250.

[23]. Hayes, B \& Stivers, T. (1996). A phonetic account of postnasal voicing. Los Angeles: Department of Linguistics, U C, Los Angeles.

[24]. Hayes, B \& Stivers, T. 2000). Postnasal voicing. Los Angeles: Department of Linguistics, University of California, Los Angeles.

[25]. Hyman, L. M. (2001). The limits of phonetic determinism in phonology: *NC revisited. In E. Hume E. \& K. Johnson (Eds.), The role of speech perception in phonology. San Diego: Academic Press.

[26]. Hyman, L. M \& Ngunga, A. (1997). Two kinds of moraic nasal in Ciyao. Studies in African Linguistics 26: 131-163.

[27]. Johnson, K. (2003). Acoustic and auditory phonetics. Malden MA: Blackwell.

[28]. Kager, R. (1999). Optimality theory. Cambridge: Cambridge University Press.

[29]. Kenstowicz, M \& Kisseberth, C. (1977). Topics in phonological theory. New York: Academic Press.

[30]. Kurisu, K. (2001). The phonology of morpheme realization. PhD thesis, University of California, Santa Cruz.

[31]. Lass, R. (1984). Phonology: An introduction to basic concepts. Cambridge: Cambridge University Press.

[32]. Lombardi, L. (1999). Positional faithfulness and voicing assimilation in OT. Natural Language and Linguistic Theory, 17, 267-302.

[33]. Lubowicz, A. (2003). Contrast preservation in phonological mappings. Doctoral dissertation, University of Massachusetts, Amherst.

[34]. Maddieson, I \& Ladefoged, P. (1993). Phonetics of partially nasal consonants. In M. K. Huffman \& R. Krakow (Eds.), Nasals, nasalization and the velum. San Diego: Academic Press, 251-301.

[35]. McCarthy, J. J. (2002). A thematic guide to Optimality theory. Cambridge: Cambridge University Press.

[36]. McCarthy, J. J. (2004). Optimality theory in phonology: A reader. Malden, MA: Blackwell.

[37]. McCarthy, J. J. \& Prince, A. S. (1993). Prosodic morphology 1: Constraint interaction and satisfaction. University of Massachusetts and Rutgers University.

[38]. McCarthy, J. J. \& Prince, A. S. (1995). Faithfulness and reduplicative identity. University of Massachusetts Occasional Papers in Linguistics, 18, 249-384.

[39]. Morelli, F. (2003). The relative harmony of /s + stop/obstruent ). In C, Fery \& R. van der Vijver (Eds.), The syllable in Optimality Theory. Cambridge: CUP.

[40]. Mutonyi, N. (2000). Aspects of Bukusu morphology and phonology. Doctoral dissertation, Ohio State University, Columbus

[41]. Myers, S. (1997). OCP effects in Optimality theory. NNLT, 15, 847-892.

[42]. Nandelenga, H. S. (2008). Constraints on prefix copying in Lubukusu reduplication. MA screening paper. University of Southern California, Los Angeles.

[43]. Nandelenga, H. S. (2013). Constraint interaction in the syllabic phonology of Lubukusu: An Optimality Theory Account. Doctoral dissertation, Kenyatta University.

[44]. Nganga, W.S. (2008). The tone structure of selected Lubukusu verbs and nouns. MA thesis, Kenyatta University.

[45]. Ngunga, A. (2000). Phonology and morphology of Ciyao verb. Stanford: CSLI Publications.

[46]. Ohala, J. J. (1995). Nasal loss before voiceless fricatives: A perceptually-based sound change. In C. A. Fowler (Ed.), Rivista di Linguistica, 7, 125-144.

[47]. Ohala, J. J. (1997). Aerodynamics of phonology. Proceedings of 4th S.I conference on Linguistics, 92-97.

[48]. Ohala, J. J. \& Kawasaki, H. (1997). Alternative to the sonority hierarchy for explaining segmental sequential constraints. In S. E. Jahr (Eds.), Trends in Linguistic Studies and Monographs $100: 343-365$. Berlin: Mouton de Gruyter.

[49]. Ohala, J. J \& Ohala, M. (1993). The phonetics of nasal phonology: Theorems and data. In M. K. Huffman \& R. Krakow (Eds.), Nasal, nasalization and the velum. San Diego: Academic Press.

[50]. Padgett, J. (1995). Stricture in Feature Geometry. Stanford: CSLI Publications.

[51]. Pater, J. (1996). *NC.. In Kusumoto (Ed.), Proceedings of NELS, 26, 227-39. 
[52]. Pater, J. (1999). Austronesian nasal substitutions and other NC effects. In R. Kager, H. van der Hulst \& W. Zonneveld (Eds.), Phonology-morphology interface. Oxford: OUP.

[53]. Pater, J. (2001). Austronesian nasal substitution revisited: What is wrong with *NC (and what's not). In L. Lombardi (Ed.), Segmental phonology in Optimality theory. Cambridge: Cambridge University Press.

[54]. Prince, A \& Smolensky, P. (1993/2004). Optimality theory: Constraint interaction in Generative grammar. Rutgers University. Malden Mass.: Blackwell.

[55]. Raphael, L. J., Borden, G. J \& Harris, K. S (2007). Speech science primer: Physiology, acoustics and perception of speech. New York: Lippincott Williams \& Wilkins.

[56]. Smith, J. L. (2003). Onset sonority constraints and subsyllabic structure. In R. R. John, A.P Markus \& N. Friedrich (Eds.), Phonologica. New York: Mouton de Gruyter.

[57]. Smolensky, P. (1996). The initial state and 'Richness of the Base' in Optimality Theory. Baltimore: Department of Cognitive Science, John Hopkins University.

[58]. Steriade, D. (1999). Phonetics in phonology: The case of laryngeal neutralization. UCLA Working Papers in Linguistics 2. Los Angeles: Department of Linguistics, UCLA.

[59]. Trommer J. (2008). Multiple-feature mutation and realize morpheme. In F. Heck., G. Muller \& J.Trommer (Eds.), Varieties of Competition 87:163-182. Linguistiche Arbbets Berichte, University of Leipzig.

[60]. Wasike, A. (2004). Hiatus resolution in Lubukusu. An MA screening paper. Cornell University, Ithaca.

[61]. Westbury, J \& Keating, P. (1986). On the naturalness of stop consonant voicing. Journal of Linguistics 22: 145-166.

[62]. Yu Cho, Y \& King, T. H. (2003). Semisyllables and universal syllabification. In C, Fery \& R. van der Vijver (Eds.), The syllable in Optimality theory. Cambridge: CUP 